Dipartimento di Scienze Statistiche

Sezione di Statistica Economica ed Econometria

Francesca Di lorio Stefano Fachin

\title{
Savings and Investments in the OECD: a panel cointegration study with a new bootstrap test
}

DSS Empirical Economics and Econometrics Working Papers Series 


\section{DSS Empirical Economics and Econometrics Working Papers Series ISSN 2279-7491}

2011/1 Massimo Franchi, Paolo Paruolo "Normal forms of regular matrix polynomials via local rank factorization"

2011/2 Francesca Di lorio, Stefano Fachin "A Sieve Bootstrap range test for poolability in dependent cointegrated panels"

2011/3 Maria Grazia Pittau, Shlomo Yitzhaki, Roberto Zelli "The makeup of a regression coefficient: An application to gender"

2011/4 Søren Johansen "The analysis of nonstationary time series using regression, correlation and cointegration - with an application to annual mean temperature and sea level"

2011/5 Mario Forni, Marc Hallin, Marco Lippi, Paolo Zaffaroni "OneSided Representations of Generalized Dynamic Factor Models"

2012/1 Marco Avarucci, Eric Beutner, Paolo Zaffaroni "On moment conditions for Quasi-Maximum Likelihood estimation of multivariate GARCH models"

Dipartimento di Scienze Statistiche Sezione di Statistica Economica ed Econometria

"Sapienza" Università di Roma

P.le A. Moro 5-00185 Roma - Italia

http://www.dss.uniromal.it 


\title{
Savings and Investments in the OECD: a panel cointegration study with a new bootstrap test
}

\author{
Francesca Di Iorio \\ University of Naples Federico II
}

\author{
Stefano Fachin* \\ University of Rome "La Sapienza"
}

\begin{abstract}
In this paper we test for the existence of a long-run savings-investments relationship in 18 OECD economies over the period 1970-2007. Although individual modelling provides only very weak support to the hypothesis of a link between savings and investments, this cannot be ruled out as individual time series tests may have low power. We thus construct a new bootstrap test for panel cointegration robust to short- and long-run dependence across units. This test provides evidence of a long-run savings-investments relationship in about half of the OECD economies examined, including USA and Japan, but not Germany. The elasticities are however often smaller than 1 , the value expected under no capital movements.

JEL codes: C23, C15, E2

Keywords:Savings, Investments, Feldstein-Horioka puzzle, OECD, Panel Cointegration, Stationary Bootstrap.

$\left.{ }^{*}\right)$ corresponding author. e-mail: s.fachin@caspur.it; tel: +39-06-49910834.
\end{abstract}




\section{$1 \quad$ Introduction $^{1}$}

From the fundamental macroeconomic relationship $Y=C+I+B$ (where as usual $Y$ denotes Gross Domestic Product (GDP), $C$ consumption, $I$ capital formation and $B$ the current account) we know that in open economies capital formation is not constrained by domestic savings $(S=$ $Y-C$ ), as $I=S-B$. However, Feldstein and Horioka (1980) documented a close correlation between savings and investments as ratios of GDP (hereafter, simply savings and investment ratios) in 16 OECD economies ${ }^{2}$ over the period 1960-1974. This evidence, christened "FeldsteinHorioka puzzle" (in fact "the mother of all puzzles", according to Obstfeld and Rogoff, 2000) for its stark contrast with the prevailing perception of capitals as mobile enough to make the external constraint not binding, has stirred an enormous literature. The survey by Apergis and Tsoumas (2009) lists nearly 200 references, many of which empirical analyses greatly differing for methods applied and data studied. While Feldstein and Horioka (hereafter FH) used a crosscountry regression of time-averaged variables, time series or panel studies now largely prevail in the literature. Since both saving and investment ratios are generally non stationary ${ }^{3}$, in the time domain the interest focuses on the existence of a long-run equilibrium relationship. A possible reason to expect such an equilibrium relationship to hold is the so-called "national long-run budget constraint" (Taylor, 2002): if either market forces or policy actions prevent indefinetely negative (or positive) current accounts, savings and investment must cointegrate with a unit coefficient.

However, clear and robust conclusions proved hard to reach empirically. The variability of the samples studied with respect to both the countries (OECD, EU or LDC's) and the time period creates a comparable variability of results. A first conclusion drawn by Apergis and Tsoumas (2009) is that overall the evidence of a saving-investment relationship is weaker for developing countries than for richer ones. In view of the typical importance for the former of foreign aid and direct investments this is not surprising ${ }^{4}$. In the OECD economies early evidence generally provided strong support to the existence of a one-to-one savings-investment relationship, but later studies are much more cautious. For instance, Jansen (1996) on the basis of a variety of tests concluded strongly in favour of a long-run savings-investment relationship for a sample of 20 OECD economies from the early 1950's to the early 1990's. Approximately over the same period, Ho (2002) found such a relationship to hold in 10 out of the 12 countries examined (OECD plus Argentina). On the other hand, using datasets starting in 1960 and ending in the early 1990's, Kim (2001) never rejected no cointegration for a panel of 19 OECD economies and Coiteux and Olivier (2000) did it only in four cases out of a slightly larger group of 22 countries. Analogously, Kollias, Mylonidis and Paleologou (2006) using Pesaran, Shin and Smith (2001) bounds testing found evidence of a long-run relationship only in about half of

\footnotetext{
${ }^{1}$ This is a completely revised version of a paper previously circulated with a similar title. Research supported by the Department TEOMESUS of the University of Naples Federico II, University of Rome "La Sapienza" and MIUR. Comments and suggestions from participants to the workshop "Factor Structures for Panel and Multivariate Time Series Data" (Maastricht, September 2008), and seminars at the University of Rome "Tor Vergata" and the Treasury Department of the Italian Ministry of Economy and Finance are gratefully acknowledged. Thanks also to Massimo Franchi for helpful discussions. We are grateful to Yoosoon Chang and Chi Mai Nguyen for sharing their programs for the computation of the IV test. The usual disclaimers apply. Correspondence to: s.fachin@caspur.it,fdiiorio@unina.it.

${ }^{2}$ Austria, Australia, Belgium, Canada, Denmark, Finland, Germany, Greece, Ireland, Italy, Japan, Netherlands, Portugal, Sweden, UK, USA.

${ }^{3}$ Although ratios obviously lie in the $[0,1]$ interval, modelling is based on the logs, which are bounded only above. Since both ratios are typically small (around 0.20 for the OECD economies between 1970 and 2007) the upper bound is empirically irrelevant, and the variables may actually behave as realizations of unit root processes.

${ }^{4}$ For instance, Rocha (2009) found the mean coefficient over 12 Latin American countries to be only slightly larger than 0.50 , hence much smaller than the unity coefficient expected under no capital mobility.
} 
the $15 \mathrm{EU}$ economies examined from 1962 to 2002. With similar results a different stream of the literature concentrated, rather than on testing if a relationship exists, on measuring it and exploring its determinants. Coakley, Fuertes and Spagnolo (2004) found mean group estimates for 12 OECD countries over the period 1980-2002 to be small and not significant, concluding that the "Feldstein-Horioka puzzle may be history". The most obvious explanation of this decreasing correlation is the increasing financial integration, but Herwartz and Xu (2010) showed that other factors (degree of openness, age dependency ratio, governement spending) also had a significant effect.

Obviously, the problem with the evidence of no rejection rewieved above is that it may be merely due to low power of the tests employed. Acknowledging this point, Pelgrin and Schich (2008) and Chakrabarti (2006) applied panel cointegration tests respectively to 20 OECD economies and essentially the entire world (126 economies) over the last four decades of the XX century. In both cases the panel cointegration tests support the existence of a saving-investment relationship, thus apparently overturning the results of the time series tests. However, the tests adopted assume independence across units. Since this is unlikely to hold for many closely integrated economies, the tests may be suspected to be severely oversized (Banerjee, Marcellino and Osbat, 2004) and the rejections spurious. Indeed, Banerjee and Zangheri (2003) showed the evidence in favour of cointegration to depend strongly on the existence of cross-country cointegration.

Summing up, the question if, quoting Blanchard and Giavazzi (2002), we are close to "the end of the Feldstein-Horioka puzzle" is both open and challenging. To answer it we need to choose carefully both data and methods. Now, even the most updated studies on OECD economies often examine periods starting around 1960 and not extending much beyond $2000^{5}$. Hence, on one hand they include one or two decades of strict capital controls (see e.g., OECD, 2002), on the other they fail to cover the most recent years of accelerating financial globalisation. On the contrary, we will use a sample starting in 1970 and ending in $2007^{6}$.

From the econometric point of view our task is particularly challenging. As argued above, failure to reject the null hypothesis, which in our case is no saving-investment relationship, can be taken as a convincing piece of evidence only if a powerful statistical procedure is used. Since, as mentioned above, the savings and investment ratios are very likely to be $I(1)$, no relationship means no cointegration, and we know that with a sample of 38 observations standard no cointegration tests should be expected to be not very powerful. Moreover, the question is on the general validity of the FH puzzle, rather than in some given country: it is thus quite natural to turn to panel procedures ${ }^{7}$. To this end we need a powerful panel cointegration test robust to short- and long-run dependence across units. As we see, none of the currently available tests is fully suitable for our task: we will then develop a new test with the desired properties.

We shall now first examine the data and carry out some standard time series analysis for the individual economies (section 2). We overall find only some weak support for a relationship

\footnotetext{
${ }^{5}$ An exception is Rao, Tamazian and Kumar (2010) who examine data up to 2007. However, their study is based on GMM, valid only for stationary variables (Kitamura and Phillips, 1997), and hings on the highly restrictive assumption of homogenous coefficients, so that its conclusions cannot be considered reliable.

${ }^{6}$ Since the 2008 financial crisis might have caused a break in the relationship it is not adivsable to extend the sample after 2007. Note that our aim is thus radically different from, e.g., Hoffmann's (2004), who investigated the validity of the $\mathrm{FH}$ equation over periods stretching for about 150 years, from the mid-XIX century to the early 1990's.

${ }^{7}$ In fact, the evidence from studies on multiple units (here, countries) is inevitably evaluted in an informal panel perspective, with conclusions holding for a large fraction of the cases considered as supported by the data. Clearly, a formal testing procedure, such as a panel test, is preferable.
} 
between savings and investment. To exclude that this may be simply due to the low power of the tests and to reach a conclusion for the panel based on a formal testing procedure we construct (section 3) and evaluate by simulation (section 4) a suitable, powerful bootstrap panel cointegration test. Applying this test to our dataset (section 5) we conclude that a long-run savings-investments relationship holds in about half of the OECD economies examined. Some overall conclusions are drawn in section 6 .

\section{Savings and Investments in the OECD, 1970-2007}

We shall study a panel including the 18 core OECD countries: Austria, Australia, Belgium, Canada, Denmark, Finland, France, Germany, Greece, Ireland, Italy, Japan, Netherlands, Portugal, Spain, Sweden, UK, USA. Eleven of this countries adopted the Euro in 1999. The data are from the OECD.stat database, with investment defined as gross capital formation and savings as net savings plus consumption of fixed capital. More details are provided in section 7.2 in the Appendix. Plots of savings and investment ratios for the individual countries are reported in Figs. 1 and 2. Overall, the visual impression is that the variables often did follow closely related paths. The most notable exceptions are Greece, Ireland and the Netherlands. In Greece the investment ratio has indeed consistently been much higher than the saving ratio (of course, we now know that this led to the 2009 debt crisis; see European Commission, 2010), while in Ireland this happened only until the mid-90's. Finally, in the Netherlands, on the opposite, savings always exceeded investments, with a widening differential. It is interesting to see that in the USA, where as well-known savings always fell short of investments, the two variables nevertheless share some large swings (troughs in early 1990's and around 2004, peak in early 2000 's); very much the same holds for Australia. Finally, in some countries the association seems to became weaker after breakpoints varying between the early (Belgium and Finland) and the late 1990's (Portugal, Spain, perhaps Germany). In the latter case the timing naturally suggests a possible influence of the introduction of the Euro in 1999 (for Portugal, where savings follow a negative trend not shared by investments, this view is supported by Blanchard and Giavazzi, 2002). Although breaks are clearly a potentially important issue, this paper will be limited to fixed-parameter models, leaving the generalisation to breaking models to future research.

Consistently with this graphical evidence and with the literature, the results of ADF unit root tests, reported in detail in Table A1 in the Appendix, are largely in favour of unit roots. The only clear exception is investments in Portugal, for which the unit root hypothesis is rejected with a $p$-value of $0.6 \%$. In the Netherlands and UK for the same variable the $p$-values are borderline with respect to the traditional 5\% threshold (respectively, 5.0\% and 5.1\%). Given that savings and investment ratios are generally, but not always, non-stationary, we model their relationship using the Auto Regressive Distributed Lags (ARDL) approach by Pesaran et al. (2001). This approach can be used to test for the existence of a level relationship between pairs of both stationary and non-stationary variables. For a given country $i$ the starting point is the conditional dynamic model

$$
\Delta i_{t}=\psi+\beta_{1} s_{t-1}+\beta_{2} i_{t-1}+\sum_{i=0}^{p_{1}} \gamma_{1 i} \Delta s_{t-i}+\sum_{i=1}^{p_{2}} \gamma_{2 i} \Delta i_{t-i}+\varepsilon_{t}
$$

where $i_{t}=\ln \left(\right.$ Investment $\left._{t} / G D P_{t}\right)$ and $s_{t}=\ln \left(\right.$ Savings $\left._{t} / G D P_{t}\right)$. Equation (1) provides a basis for both estimation of the long-run saving-retention ratio as $\beta=-\beta_{1} / \beta_{2}$ and for tests of the null hypothesis of no relationship between the levels of the variables. To this end Pesaran et al. (2001) recommend the $F$-test for $H_{0}: \beta_{1}=\beta_{2}=0$, while Banerjee, Dolado and Mestre (1998) proposed as a cointegration test the $t$-test for $H_{0}: \beta_{2}=0$. We thus estimated equation (1) for 
each country of our panel, selecting the dynamic structure on the basis of the standard model selection criteria (AIC, Hannan-Quinn, Schwarz) and checking the presence of autocorrelation in the residuals through LM tests. The main results are reported in Table 1, with details of dynamic structure and diagnostics in Table A2 in the Appendix.

From Table 1 we can see that both the $F$-test for $H_{0}: \beta_{1}=\beta_{2}=0$ and the $t$-test for $H_{0}: \beta_{2}=0$ mostly fail to reject even at $10 \%$ the hypothesis of no level relationship between savings and investment. More precisely, taking into account the results of the ADF tests about the time series properties of the series, evidence of a relationship is found only in six cases out of 18: Australia, Greece (where the elasticity is however, as expected, negative, hence the relationship spurious), Italy, Japan, Portugal and UK. Excluding Greece, in half of these cases the saving-retention ratio is smaller than 1 (Australia, Portugal, UK), in two cases slightly larger than 1 (Italy, Japan).

Trying to shed some more light on the issue we also computed Engle-Granger $(E G)$ cointegration tests (Table 2). Given the exploratory nature of these tests we compute them for all countries, including Portugal where one of the variables is stationary according to the ADF tests. Excluding Greece, the $E G$ tests are significant at 5\% in three cases (Japan, Portugal, UK) plus one more at 0.10 (Australia), thus delivering a 7picture essentially similar to that of the ARDL bounds test.

Summing up, a long-run savings-investment relationship seem to exist in a minority of the countries of our panel, with coefficients often far from the theoretically expected value of 1 . Should we conclude that there is no FH puzzle any more? Not necessarily. As discussed above, we may fail to reject the hypothesis of no long-run relationship simply because of the small sample size. We need a more powerful procedure. This will be constructed in the next section. 


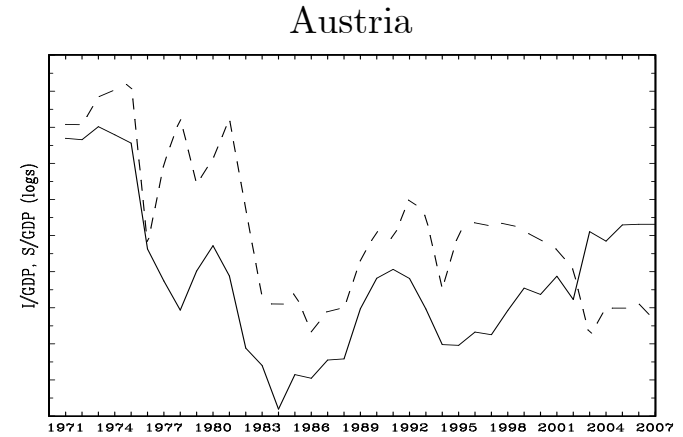

Belgium

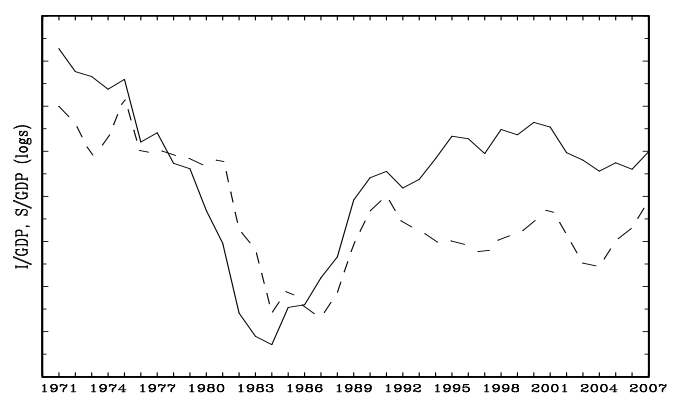

Denmark

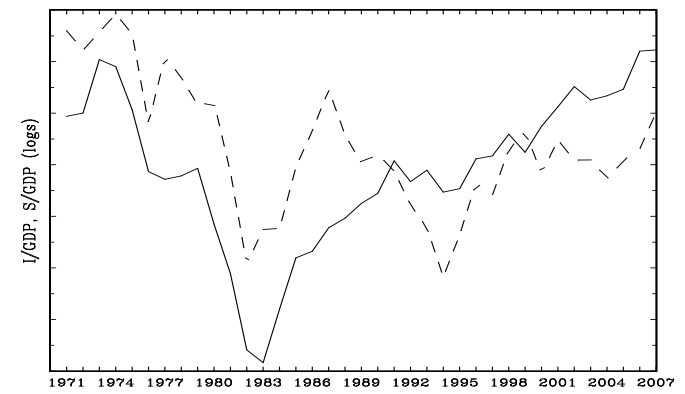

France

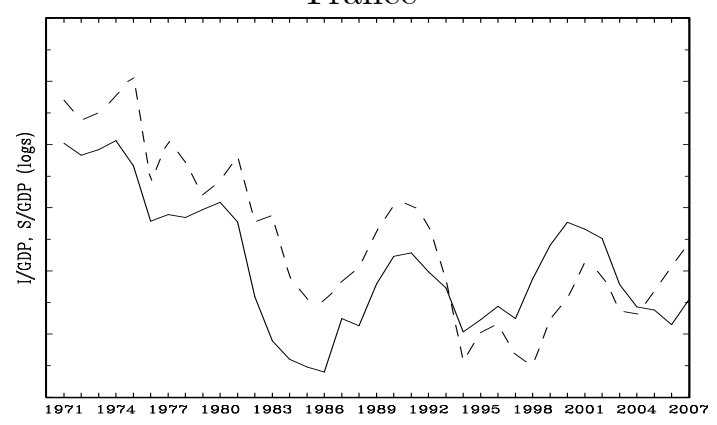

Australia

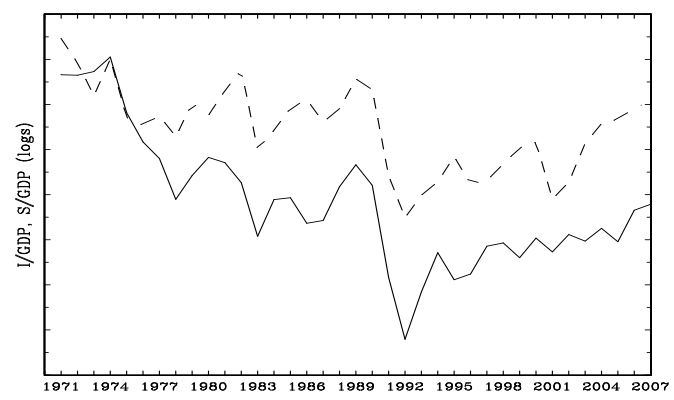

Canada

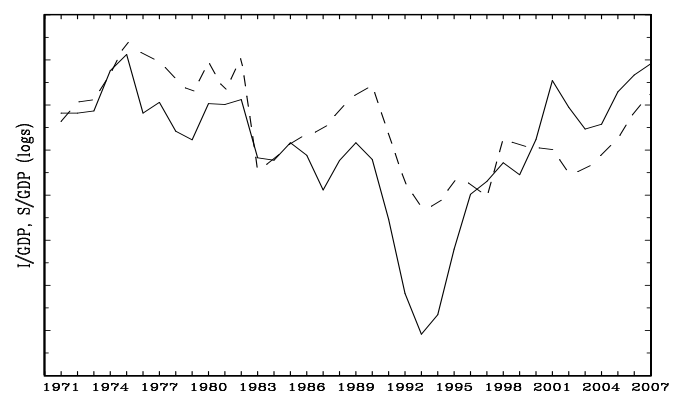

Finland

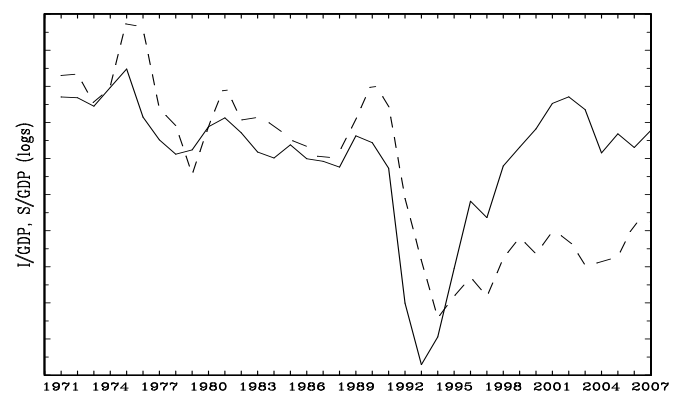

Germany

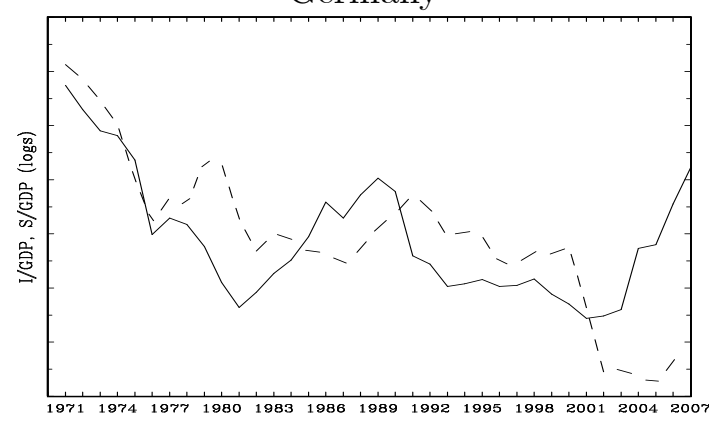

Fig. 1 Savings/GDP (solid line) and Investment/GDP (dashed line), 1970-2007 (logs). 


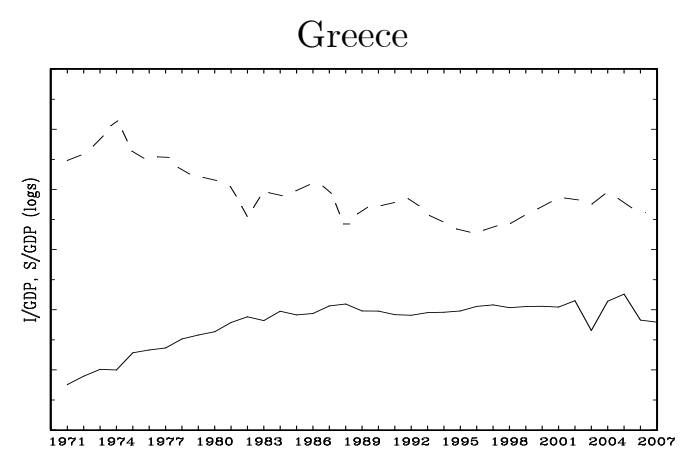

Italy

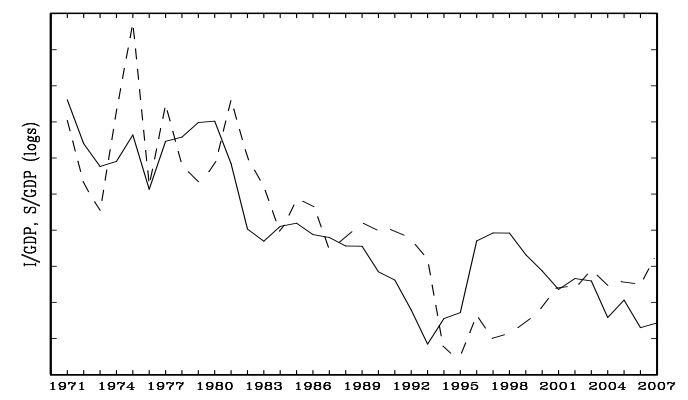

Netherlands

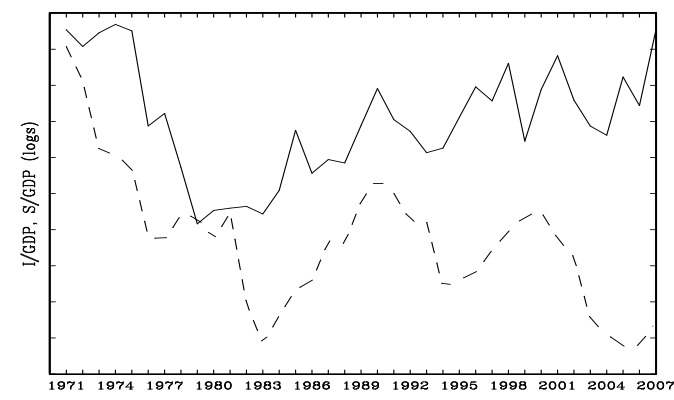

Spain

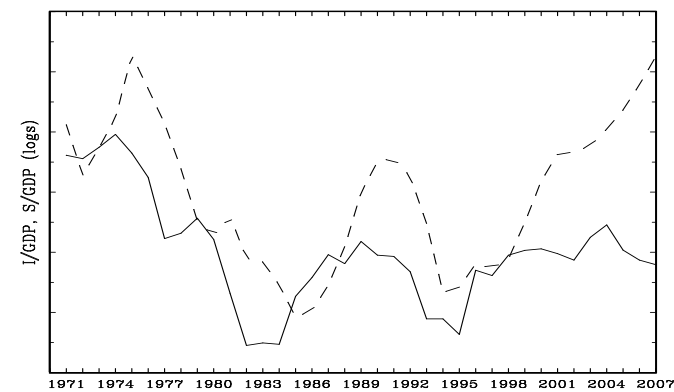

UK

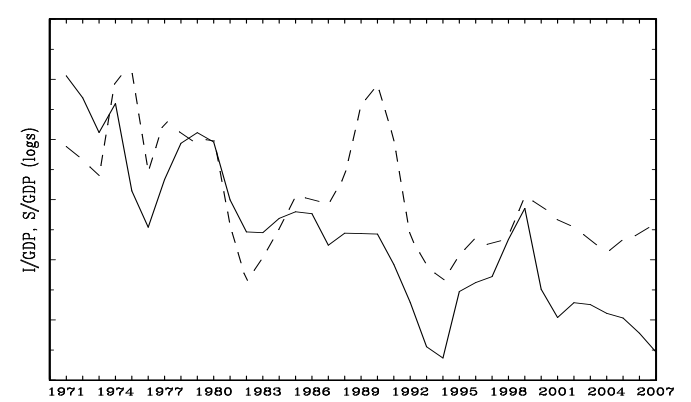

Ireland

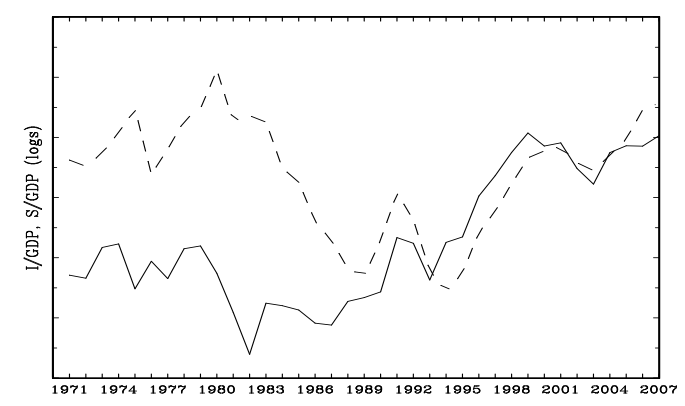

Japan

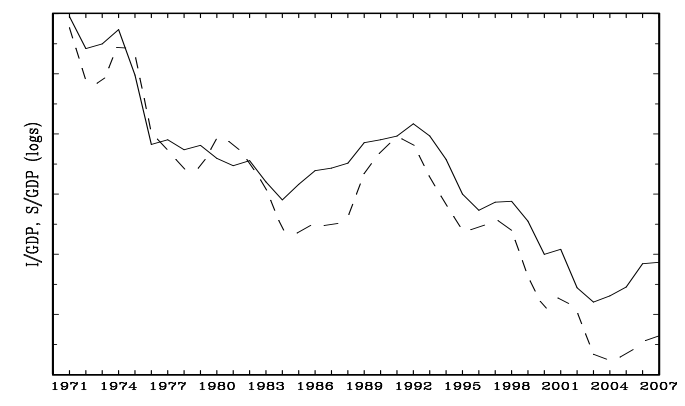

Portugal

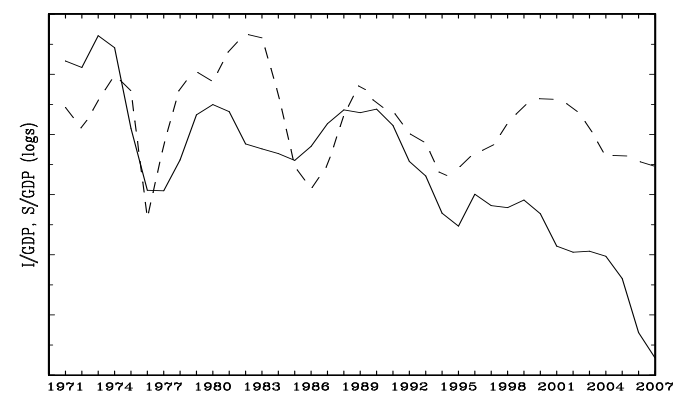

Sweden

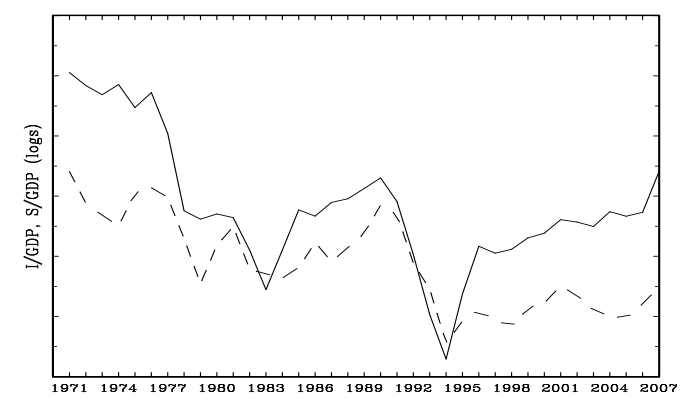

USA

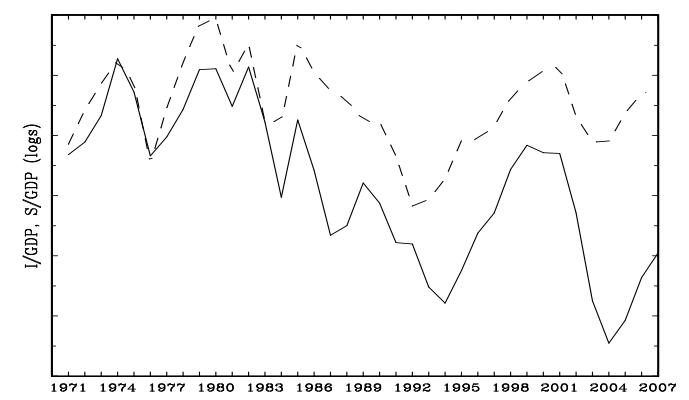

Fig. 2 Savings/GDP (solid line) and Investment/GDP (dashed line), 1970-2007 (logs). 
Table 1

Saving and Investments in the long-run:

ARDL conditional modelling and tests of no level relationship

\begin{tabular}{|c|c|c|c|c|c|c|}
\hline & Austria & Australia & Belgium & Canada & Denmark & Finland \\
\hline$\beta$ & 0.48 & 0.69 & -1.78 & 0.93 & 0.62 & 3.17 \\
\hline$F$ & 1.62 & $5.05^{*}$ & 3.83 & 2.51 & 1.33 & 4.30 \\
\hline$t$ & -1.78 & $-2.89^{*}$ & -0.60 & -1.57 & -1.42 & -1.32 \\
\hline & France & Germany & Greece & Ireland & Italy & Japan \\
\hline$\beta$ & 1.38 & 1.42 & -1.17 & 1.18 & 1.14 & 1.32 \\
\hline$F$ & 1.70 & 1.59 & $7.42^{*}$ & 2.38 & $6.52^{*}$ & $8.56^{*}$ \\
\hline$t$ & -1.58 & 1.38 & $-3.84^{*}$ & -1.22 & $-3.41^{*}$ & $-3.90^{*}$ \\
\hline & Netherlands & Portugal & Spain & Sweden & $U K$ & $U S A$ \\
\hline$\beta$ & 0.27 & 0.25 & 1.21 & 1.75 & 0.67 & 0.28 \\
\hline$F$ & 1.47 & $5.96^{*}$ & 3.67 & 2.71 & $5.17^{*}$ & 2.62 \\
\hline$t$ & -1.71 & $-3.45^{*}$ & -2.54 & -0.76 & $-3.11^{*}$ & -2.20 \\
\hline
\end{tabular}

Table 2

Saving and Investments in the long-run:

Engle-Granger cointegration tests

\begin{tabular}{cccccc}
\hline \hline Austria & Australia & Belgium & Canada & Denmark & Finland \\
\hline-0.35 & -3.23 & -1.69 & -2.23 & -2.31 & -1.34 \\
{$[0.97]$} & {$[0.09]^{*}$} & {$[0.68]$} & {$[0.42]$} & {$[0.38]$} & {$[0.82]$} \\
\hline France & Germany & Greece & Ireland & Italy & Japan \\
\hline-1.64 & -0.88 & -3.55 & -1.45 & -2.78 & -4.24 \\
{$[0.71]$} & {$[0.92]$} & {$[0.04]^{* *}$} & {$[0.78]$} & {$[0.19]$} & {$[0.003]^{* *}$} \\
\hline Netherlands & Portugal & Spain & Sweden & UK & USA \\
\hline-2.23 & -3.95 & -1.92 & -2.07 & -3.47 & -3.05 \\
{$[0.42]$} & {$[0.01]^{* *}$} & {$[0.57]$} & {$[0.50]$} & {$[0.04]^{* *}$} & {$[0.12]$} \\
\hline \hline
\end{tabular}

asymptotic $p$-values in brackets; ${ }^{*}{ }^{* *}$ : significant at $0.10,0.05$. 


\section{Testing cointegration in panels}

\subsection{Overview}

The rate of expansion of the literature on the analysis of non-stationary panels, as revealed e.g., by a comparison of the list of references in the surveys by Banerjee (1999) and Breitung and Pesaran (2008) or Banerjee and Wagner (2009) is impressive. This growing interest is due to good reasons: first, as in our case, many important economic questions are naturally framed in a panel perspective; second, adding the cross-section dimension may grant considerable improvements of the small samples properties of testing procedures. Obviously, in order to exploit the panel dimension in asymptotic testing some restrictions must be imposed ${ }^{8}$. First generation tests (e.g., Kao, 1999, and Pedroni, 2004) followed the rather drastic option of imposing homogeneity, hence designing pooled tests, or assuming independence. Most later contributions took the more appealing route of modelling dependence. Although modelling the dependence between the test statistics is possible (Westerlund and Constantini, 2009), the more popular option is that of assuming the existence of common factors in the variables or the cointegrating residuals (Banerjee and Carrion-i-Silvestre, 2006, Gengenbach, Palm and Urbain, 2006, Westerlund, 2008). In the latter case, removing the dependence using principal components methods (Bai and $\mathrm{Ng}, 2004$ ) allows use of standard tests for independent panels. Unfortunately, none of these approaches have provided fully satisfactory solutions yet. Westerlund and Constantini (2009) rely upon the restrictive assumptions of weakly exogenous right-hand side variables and constant covariance across test statistics. Although the authors claim the test to be somehow robust to more general forms of dependence, on the basis of the reported simulations its size and power properties do not appear particularly appealing, especially for small sample sizes. As Gengenbach et al. (2006) explicitly admit, the need of large sample sizes is also a weakness of the common factor approach. Thus, although investigating the common factor structure of the data could be very important for its own sake, in many empirical applications the available information set may simply be not rich enough. A second problem of factor methods is the need to choose some form of structure of the factors. For instance, Banerjee and Carrion-iSilvestre (2006) and Westerlund (2008) allow for common factors in the cointegrating residuals but not in the variables themselves. These are allowed by Bai and Carrion-i-Silvestre (2005) and Gengenbach et al. (2006), but at the cost of other restrictions: the former assume homogeneous cointegrating vectors, and the latter that the matrix of factor loadings is full rank and blockdiagonal. Hence, the empirically important case of of a single source of non-stationarity is ruled out. For instance, in our case the national stochastic trends in savings (and, if cointegration holds, investments) may be linked to a global stochastic trend.

Completely different perspectives have been favoured by Chang and Nguyen (2011) on one hand, and Fachin (2007) and Westerlund and Edgerton (2007), on the other. Chang and Nguyen (2011), building upon Chang (2002), developed a instrumental variable (IV) test robust to general dependency among the errors of the equations of the different units. Cointegration across units is also admitted, but in this case some complications arise, the main one being that the instruments require an ordering of the units. The results and properties of the test should be invariant to the chosen ordering in large samples, but not necessarily so in small ones (see Chang and Song, 2009). Since cross-unit cointegration is a very likely feature of our dataset we expect the IV test not be fully suitable for our task.

Finally, Fachin (2007) and Westerlund and Edgerton (2007) developed two different boot-

\footnotetext{
${ }^{8}$ We are excluding the panel full information maximum likelihood approach (Groen and Kleibergen, 2003) which, requiring the time dimension to be much larger than the cross-section dimension, cannot be applied to our dataset (nor to most macroeconomic panels in general),
} 
strap algorithms conditional on the cross-section linkages as present in the dataset at hand. In other terms, no attempt is made to model the dependence structure, which is simply reproduced in the pseudodata. More precisely, Fachin (2007) applied the Continuous-path block bootstrap (Paparoditis and Politis, 2001, 2003) separately to the right- and the left-hand side variables, hence generating unrelated pseudoseries obeying the null hypothesis of no cointegration, while Westerlund and Edgerton (2007) developed a sieve bootstrap procedure. However, both tests have some weaknesses. The algorithm by Fachin (2007) destroys any relationship between the modelled variables, not only long-run ones. Hence, the bootstrap pseudodata obey not only the null hypothesis which we are interested in testing (no long-run relationship) but also that of no short-run relationships. On the other hand, the sieve bootstrap applied by Westerlund and Edgerton (2007) hinges upon the assumption of a linear structure of the cointegrating residuals.

Summing up, we need to improve on the available methods. To this end, a natural route is to extend to the analysis of cointegration the residual-based Stationary Bootstrap (RSB) test for unit roots developed by Parker, Paparoditis and Politis' (2006), henceforth PPP, which does not require any assumptions on the form of time dependence of the residuals. The test by PPP is closely related to the block bootstrap panel unit root test shown by Palm, Smeekes and Urbain (2008) to be asymptoticall valid; the key advantage of the Stationary Bootstrap over the block bootstrap is that the resampled pseudo-series series are stationary, hence the name (Politis and Romano, 1994). In both cases the resampling involves chaining blocks of observations of the originary series starting at random locations, with the difference that in the Stationary Bootstrap the length is also random, while in the block bootstrap it is fixed.

\subsection{Panel cointegration testing via residual-based bootstrap}

To fulfill the task described at the end of the previous section we propose a test of the "group mean" type (i.e., computed as a summary measure of the individual no cointegration statistics; see Pedroni, 1999), with inference carried out, as mentioned above, through the bootstrap. As an individual no cointegration statistic we will use the two-step Engle-Granger type test by Hansen (1990), which, as we will see below, lends itself naturally to a bootstrap implementation. We shall now first describe the set-up, the computation of the individual two-step statistics, and the bootstrap algorithm. The panel dimension of the testing procedure will be brought into the discussion in a second moment, in two different ways. The convenient assumption of a panel with independent units will be made in order to show analytically that a panel test based on the mean of the individual statistics is asymptotically valid; the proof is described in detail in the Appendix (section 7.1). The empirically more relevant case of dependent panels will be examined in the simulation experiment described in the next section, where we will show that panel cointegration tests based on the mean, the median and the maximum of the individual no cointegration statistics deliver good size and power performances for panels with common factors.

We consider a standard set-up. An integrated bivariate process $z_{i t}=\left(y_{i t}, x_{i t}\right)^{\prime}$, where $t=1 \ldots T$ and $i=1 \ldots N$ index respectively the time periods and the cross-section units, is assumed to be such that

$$
\begin{aligned}
& x_{i t}=x_{i t-1}+u_{i t}^{x} \\
& y_{i t}=\beta_{i} x_{i t}+u_{i t}^{y}
\end{aligned}
$$

where $u_{i t}^{x} \sim N\left(0, \sigma_{x i}^{2}\right)$ and $u_{i t}^{y}$ is an error term whose properties determine the short- or long-run nature of the linear relationship between the two variables. When $u_{i t}^{y}$ is stationary $(2 \mathrm{~b})$ defines a level (cointegrating) relationship between the two variables with cointegrating coefficient $\beta_{i}$, 
while when $u_{i t}^{y}$ is $I(1)$ the relation is best interpreted as the first difference, short-run equation

$$
\Delta y_{i t}=\beta_{i} \Delta x_{i t}+\Delta u_{i t}^{y}
$$

in which case $\beta_{i}$ is the short-run elasticity of $y_{i t}$ to $x_{i t}$. Recalling that the panel dimension will be brought into the discussion below, define for a given unit $i$

$$
v_{i t}:=u_{i t}^{y}-\rho_{i} u_{i t-1}^{y} .
$$

When $\rho_{i}=1$ the residuals of $(2 \mathrm{~b})$ are $I(1)$, so that $y_{i t}$ and $x_{i t}$ are not cointegrated. When $\left|\rho_{i}\right|<1$ they are instead stationary, so that $y_{i t}$ and $x_{i t}$ are cointegrated. Note that, as strongly emphasised by PPP, we are not assuming an AR(1) structure for the cointegrating residuals. In other terms, equation (3) is not meant to be a model adequately capturing the memory of the $u_{i t}^{y \prime} s$, and thus the $v_{i t}^{\prime} s$ are not assumed to be white noise. In fact, equation (3) has a purely instrumental purpose: defining a parameter, $\rho_{i}$, mapping the null hypothesis of interest of no cointegration. Since $\rho_{i}=1$ implies no cointegration, the task of testing " $H_{i 0}$ : no cointegration in unit $i^{\prime \prime}$ may be conveniently carried out by a test of $H_{i 0}: \rho_{i}=1$. A natural candidate is a generalisation of the Residual-Based Bootstrap test for unit roots by PPP.

To this end we need to construct a pseudo-dataset $\left\{x_{i t}^{*}, y_{i t}^{*}\right\}$ obeying $H_{i 0}$ and reproducing the essential features of the originary data $\left\{x_{i t}, y_{i t}\right\}$. Since $x_{i t}$ is known to be $I(1)$, broadly speaking a natural way to obtain the pseudoseries $x_{i t}^{*}$ is to resample the first differences $\Delta x_{i t}$ by some algorithm valid for weakly dependent series, obtain the pseudo-differences $\Delta x_{i t}^{*}$, and finally cumulate them to obtain the $x_{i t}^{*}$. Constructing $y_{i t}^{*}$ is a more delicate issue, as we need to make sure that the pseudodata reproduce the relationship between $y_{i t}$ and $x_{i t}$, which we thus need to estimate accurately with no prior knowledge of its nature (long-run or short-run). Direct estimation of $(2 \mathrm{~b})$ would work under cointegration but not in its absence, as in this case all estimators of $\beta_{i}$ will stay random even in the limit, leading also to poor estimates of the residuals $u_{i t}^{y}$. Essentially, we are trapped in a circular problem: to have a good estimate of $(2 \mathrm{~b})$ we need to know if cointegration holds or not, which we do only if we have a good estimate of $(2 \mathrm{~b})$. The way out from the puzzle is offered by Cochrane and Orcutt's (1949) iterated regression, first exploited by Hansen (1990) to develop a multi-step no cointegration test and recently reproposed by Choi, Hu and Ogaki (2008) and Wang and Rosa (2010). The structure of a panel no cointegration test based on Hansen's multi-step procedure is the following:

Step 1 For a given unit $i$, estimate equations (2b) and (3) by OLS, obtaining estimates $\widehat{\beta}_{i}$ and $\widehat{\rho}_{i}$. For the latter it holds that

$$
\widehat{\rho}_{i}=\rho_{i}+ \begin{cases}o_{p}(1) & \text { if } \rho_{i}<1 \text { (cointegration) } \\ O_{p}\left(T^{-1}\right) & \text { if } \rho_{i}=1 \text { (no cointegration) }\end{cases}
$$

Then, quasi-difference the data using $\widehat{\rho}_{i}$ :

$$
\begin{aligned}
y_{i t}^{d} & =y_{i t}-\widehat{\rho}_{i} y_{i t-1} \\
x_{i t}^{d} & =x_{i t}-\widehat{\rho}_{i} x_{i t-1}
\end{aligned}
$$

Step 2 Apply again OLS to the equation in the quasi-differences:

$$
y_{i t}^{d}=\beta_{i}^{d} x_{i t}^{d}+u_{i t}^{d} .
$$

The two-step estimator $\widehat{\beta}_{i}^{d}$ satisfies

$$
\widehat{\beta}_{i}^{d}=\beta_{i}+ \begin{cases}O_{p}\left(T^{-1}\right) & \text { if } \rho_{i}<1 \text { (cointegration) } \\ O_{p}\left(T^{-\frac{1}{2}}\right) & \text { if } \rho_{i}=1 \text { (no cointegration) }\end{cases}
$$


(Hansen, 1990, theorem 1). The residuals estimated from (5) are:

$$
\begin{aligned}
\widehat{\widehat{u}}_{i t}^{d} & =y_{i t}^{d}-\widehat{\beta}_{i}^{d} x_{i t}^{d} \\
& =\left(y_{i t}-\widehat{\rho}_{i} y_{i t-1}\right)-\widehat{\beta}_{i}^{d}\left(x_{i t}-\widehat{\rho}_{i} x_{i t-1}\right)
\end{aligned}
$$

where the "double hat" notation for the residuals emphasises its dependence upon two estimates: the regression coefficient $\widehat{\beta}_{i}^{d}$ and the $\operatorname{AR}(1)$ coefficient $\widehat{\rho}_{i}$ used to compute the quasi-differences $y_{i t}^{d}$ and $x_{i t}^{d}$. Since $\widehat{\beta}_{i}^{d}$ and $\widehat{\rho}_{i}$ respectively satisfy (6) and (4), $\widehat{\widehat{u}}_{i t}^{d}$ is stationary under both the null (no cointegration) and alternative hypothesis (cointegration). Similarly to $\Delta x_{i t}$, it can then be resampled using any method valid for weakly dependent series, such as the Stationary Bootstrap.

Step 3 Define the residuals of the level equation (2b) with the coefficient fixed at the estimate from the quasi-difference regression:

$$
\widetilde{u}_{i t}^{y}=y_{i t}-\widehat{\beta}_{i}^{d} x_{i t}
$$

and estimate again the first-order autoregression (3) on the $\widetilde{u}_{i t}^{y \prime} s$ :

$$
\widetilde{u}_{i t}^{y}=\widetilde{\rho}_{i} \widetilde{u}_{i t-1}^{y}+\widetilde{v}_{i t}
$$

obtaining a new estimate of the autoregressive coefficient, $\widetilde{\rho}_{i}$. Thanks to the consistent estimation of the regression coefficient under the null hypothesis the $\operatorname{AR}(1)$ coefficient $\widetilde{\rho}_{i}$ is such that the limiting distributions of the coefficient statistic, $T\left(\widetilde{\rho}_{i}-1\right)$, are identical to the Dickey-Fuller distribution (Hansen, 1990, theorem 2). Note that in the rest of the paper we shall assume no cointegration to be tested through the traditional studentised statistic, which we christen "Hansen-Engle-Granger": $H E G_{i}=\left(\widetilde{\rho}_{i}-1\right) / s_{\widetilde{\rho}}$, where $s_{\widetilde{\rho}}$ is the estimated standard error of $\widetilde{\rho}_{i}$.

A "group mean" panel no cointegration test is easily obtained carrying out a fourth step:

Step 4 Once obtained the individual AR coefficients $\widetilde{\rho}_{i}$ (and the desired derived statistics, such as the $H E G_{i}$ ) for all units, compute the desired panel (no) cointegration test as some summary statistic $(G)$ of the $N$ individual tests: $G=G\left(H E G_{1}, \ldots, H E G_{N}\right)$.

As remarked in Step 3, the properties of the two-step residuals $\widehat{\widehat{u}}_{i t}^{d}$ make bootstrap inference on $G$ relatively easy. The details of the bootstrap procedure are the following ${ }^{9}$ :

Algorithm 1 RSB panel no cointegration test

1. For all units $i=1, \ldots, N$ :

1.1 Estimate $(2 \mathrm{~b})$ by OLS, obtaining $\widehat{u}_{i t}^{y}$;

1.2 Estimate (3) by OLS, obtaining $\widehat{\rho}_{i}$;

1.3 Quasi-difference the data using $\widehat{\rho}_{i}: x_{i t}^{d}=x_{i t-1}-\widehat{\rho}_{i} x_{i t-1}, y_{i t}^{d}=y_{i t-1}-\widehat{\rho}_{i} y_{i t-1}$;

1.4 Estimate the equation in the quasi-differences, $y_{i t}^{d}=\beta_{i}^{d} x_{i t}^{d}+u_{i t}^{d}$, obtaining the OLS coefficient estimate $\widehat{\beta}_{i}^{d}$ and the residuals $\widehat{\widehat{u}}_{i t}^{d}$;

\footnotetext{
${ }^{9}$ Note that, although for simplicity we considere here the case of a single right-hand side variable, the algorithm is trivially generalised to the case of multivariate models.
} 
1.5 Compute the residuals $\widetilde{u}_{i t}^{y}=y_{i t}-\widehat{\beta}_{i}^{d} x_{i t}$;

1.6 Estimate by OLS the $\operatorname{AR}(1)$ regression (9) on the residuals $\widetilde{u}_{i t}^{y}$, obtaining $\widetilde{\rho}_{i}$ and the desired (no) cointegration test statistic. In the following we shall assume this to be the popular Engle-Granger statistic: $H E G_{i}=\left(\widetilde{\rho}_{i}-1\right) / s_{\widetilde{\rho}}$, where $s_{\widetilde{\rho}}$ is the estimated standard error of the autoregressive coefficient;

2. Apply the Stationary Bootstrap to the $(T-1) \times 2 N$ matrix $\mathbf{V}=\left[\begin{array}{ll}\Delta \mathbf{x}_{1} \ldots \Delta \mathbf{x}_{N} & \widehat{\mathbf{u}}_{y 1}^{d} \ldots \widehat{\mathbf{u}}_{y N}^{d}\end{array}\right]$, where $\Delta \mathbf{x}_{i}=\left[\Delta x_{1 i} \ldots \Delta x_{T i}\right]^{\prime}, \Delta x_{i t}=x_{i t}-x_{i t-1}-(T-1)^{-1} \sum_{s=2}^{T}\left(x_{i s}-x_{i s-1}\right)$, and $\widehat{\mathbf{u}}_{i}^{d}=\left[\widehat{u}_{1 i}^{d} \ldots \widehat{u}_{T i}^{d}\right]^{\prime}$ (note that if equation (2b) does not include a constant the residuals must be centred on the mean also), obtaining a matrix of pseudo-values $\left[\Delta \mathbf{x}_{1}^{*} \ldots \Delta \mathbf{x}_{N}^{*} \mathbf{u}_{1}^{d *} \ldots \mathbf{u}_{N}^{d *}\right]$. This is achieved through the following steps:

2.1 generate $L_{1}, \ldots, L_{T}$ i.i.d. from a geometric distribution with parameter $\theta_{T}$;

2.2 for each $t \in[1, T-1]$ let $K_{t}=\inf \left\{k: L_{1}+\ldots+L_{k} \geq t\right\}$ and $M_{t}=L_{1}+\ldots+L_{K_{t}}$;

2.3 independently from the above, generate $\varsigma_{1}, \ldots, \varsigma_{K_{T}}$ i.i.d. from a uniform distribution on $\{2, \ldots, T\}$;

2.4 for all $t \in\left[1, K_{T}\right]$ set $\left[\Delta x_{1 t}^{*} \ldots \Delta x_{N t}^{*} u_{1 t}^{d *} \ldots u_{N t}^{d *}\right]=\left[\Delta x_{1 \tau} \ldots \Delta x_{N \tau} \widehat{u}_{1 \tau}^{d} \ldots \widehat{u}_{N \tau}^{d}\right]$, where $\tau=\left[\left(\varsigma_{K_{t}}+\left(t-M_{t}\right)\right) \bmod (T-1)\right]+2$;

3. Generate for each unit $i$ the pseudo-differences of the right-hand side variable using $\widehat{\beta}_{i}^{d}$ as population parameter: $\Delta y_{i t}^{*}=\widehat{\beta}_{i}^{d} \Delta x_{i t}^{*}+u_{i t}^{d *}$;

4. Cumulate the pseudo-differences $\Delta x_{i t}^{*}$ and $\Delta y_{i t}^{*}$ to obtain $I(1)$ pseudo-levels $x_{i t}^{*}$ and $y_{i t}^{*}=$ $\widehat{\beta}_{i}^{d} x_{t}^{*}+u_{i t}^{*}$, where the residuals $u_{i t}^{*}=\sum_{s=1}^{t} u_{i s}^{d *}$ obey the null hypothesis of no cointegration;

5. Repeat steps 1.1-1.6 on the datasets $\left\{y_{i t}^{*}, x_{i t}^{*}\right\}, i=1, \ldots, N$, obtaining the bootstrap counterparts of $\widehat{\beta}_{i}^{d}, \widetilde{u}_{i t}^{y}, \widetilde{v}_{i t}, \widetilde{\rho}_{i}$, namely $\beta_{i}^{d *}, \widetilde{u}_{i t}^{*}, \widetilde{v}_{i t}^{*}, \widetilde{\rho}_{i}^{*}$ and the $N$ no cointegration statistics $H E G_{i}^{*}=\left(\widetilde{\rho}_{i}^{*}-1\right) / s_{\widetilde{\rho}^{*}}$, where $s_{\widetilde{\rho}^{*}}$ is the estimated standard error of $\widetilde{\rho}_{i}^{*}$;

6. Compute the summary statistics of the individual $H E G_{i}$ statistics obtained from the originary data, $G=G\left(H E G_{1}, \ldots, H E G_{N}\right)$, and from the bootstrap pseudodata, $G^{*}=$ $G\left(H E G_{1}^{*}, \ldots, H E G_{N}^{*}\right)$

7. Repeat steps 2-6 B times;

8. Assuming the rejection region of the test is the left tail, obtain the bootstrap $p$-value as $p^{*}=\operatorname{prop}\left(G^{*}<G\right)$. Reject the null hypothesis if $p^{*}<\alpha$, where $\alpha$ is the significance level of the test (alternatively, reject $H_{0}$ if $G<c_{\alpha}^{*}$, where $c_{\alpha}^{*}$ is the $\alpha$-level critical value obtained from the distribution of the $G^{* \prime} s$ ).

In the Appendix we show that under the assumption of independence across units a test based on the mean of the individual statistics is asymptotically valid:

$$
\sup _{c \in \mathcal{R}}\left|P^{*}\left(N^{-1} \sum_{i=1}^{N} T\left(\widetilde{\rho}_{i}^{*}-1\right) \leq c \mid z_{i 1} \ldots z_{i T}\right)-P_{0}\left(N^{-1} \sum_{i=1}^{N} T\left(\widetilde{\rho}_{i}-1\right) \leq c\right)\right| \stackrel{p}{\longrightarrow} 0
$$

where $P^{*}$ is the bootstrap distribution and $P_{0}$ is the probability measure obtained under the null hypothesis of no cointegration. 
Dependent panels and tests based on order statistics are both of more difficult treatment. Since we are resampling jointly all units, intuition suggests that the dependence structure is automatically reproduced in the pseudodata. This intuition is somehow supported by the formal proof of asymptotic validity of a block bootstrap panel unit root test provided by Palm et al. (2008) in a panel with common factors. However, many different dependence structures can be conceived, especially so in DGPs with more than one right-hand side variable. Since any proof of the asymptotic validity of the test will be necessarily conditional on the assumed dependence structure, a fully general proof is by definition not possible. Well-designed simulation studies may provide arguably more useful insights, especially considering the paramount importance for applied work of small sample performance.

Before proceeding further, some remarks are in order.

(i) Choice of summary statistic. This aspect of the test, closely related with its null and alternative hypotheses, deserves a careful discussion. While there is wide agreement on the null hypothesis of panel tests, which is always $H_{0}$ : "no cointegration in all units", equivalent to $H_{0}: H E G_{i}=1 \forall i$ and $H_{0}: \rho_{i}=1 \forall i$, the alternative hypotheses is surrounded by some confusion in the literature. Even if this is seldom clearly stated (see e.g., Pedroni, 2004, and Chang and Song, 2009), in empirical panel studies allowing for heterogeneity the idea is to reject the null of no cointegration when the evidence in the opposite direction prevails, i.e. when the majority (or, briefly, most) of the units support cointegration. Concentrating for simplicity on the AR coefficient $\rho_{i}$, this implies that the alternative hypothesis of interest is $H_{1}:$ " $\rho_{i}<1$ in the majority of the units". In other terms, we want $H_{0}$ to be rejected when the mass of the distribution of the $\rho_{i}^{\prime} s$ is significantly far from 1 . This clearly suggest the median as summary statistic, so that $G=\operatorname{Median}(\boldsymbol{\rho})$, where $\boldsymbol{\rho}=\left[\rho_{1} \ldots \rho_{N}\right]$. Asymptotic tests are instead typically based on the mean (i.e., $G=N^{-1} \sum_{i=1}^{N} \rho_{i}$ ), and will thus have power not only against the desired alternative hypothesis $H_{1}$ : " $\rho_{i}<1$ in the majority of the units" but also against the hypothesis $H_{1}: " \rho_{i}<<1$ in a small number of units", which is of very little or no interest at all. Actually, in some cases an empirically interesting hypothesis is the almost opposite case $H_{1}:$ " $\rho_{i}<1$ in all units". Since in this case all $\rho_{i}^{\prime} s$ should be significantly smaller than 1 in order to reject $H_{0}$ the natural summary statistic is obviously $G=\operatorname{Max}(\boldsymbol{\rho})$. While a max test is feasible using Chang and Nguyen's (2011) IV approach, to the best of our knowledge median tests have been considered only by Fachin (2007). In our simulation experiment we will evaluate median, mean and max tests ${ }^{10}$.

(ii) Block length. An important, and still largely unsettled, aspect of block bootstrap methods is the choice of block length. In the case of the Stationary Bootstrap the length is random, and the choice to be made is on the parameter $\theta_{T}$ of the geometric distribution (step 2.1 of the algorithm), which determines the mean block length. To prove the asymptotic validity of the test PPP assume $\theta_{T} \rightarrow 0$ as $T \rightarrow \infty$, so that $\sqrt{T} \theta_{T} \rightarrow \infty$. In practice, in the finite samples used in simulation experiments rules for the mean block length such as $0.10 T$ used by Paparoditis and Politis (2001) or $1.75 \sqrt[3]{N}$, used by Palm et al. (2008), seem to deliver good results. In our simulations we will thus use fixed mean block lengths, leaving implementation of data-based methods, such as the Warp-Speed calibration of Palm et al. (2008), to future research.

\footnotetext{
${ }^{10}$ Chang and Nguyen (2011) consider also a test based on the minimum, claimed to be best suited to detect the case of cointegration holding in a small fraction of the units. Our procedure can obviously automatically handle this case, but since we do not believe it to be an empirically interesting hypothesis (in fact, it could be argued that when that is the case the panel is best defined as not cointegrated) we will not examine it.
} 
(iii) Endogeneity. Since resampling is applied to the matrix $\left[\begin{array}{llll}\Delta \mathbf{x}_{1} \ldots \Delta \mathbf{x}_{N} & \widehat{\mathbf{u}}_{y 1}^{d} \ldots \widehat{\mathbf{u}}_{y N}^{d}\end{array}\right]$ the pseudoseries are expected to reproduce any feedback from the cointegrating errors on the right-hand side variables $x_{i t}$, hence to be robust to the failure of weak exogeneity of the latter.

(iv) Deterministics. If a linear time trend is included in (2b), a constant will be included in the quasi-difference equation and in the bootstrap DGP.

(v) Comparison with sieve bootstrap. It is instructive to compare the procedure proposed here with the model-based sieve bootstrap applied by Westerlund and Edgerton (2007). In the sieve bootstrap an autoregressive linear structure for the residuals is assumed, so that (3) is replaced by an $A R(p)$ model:

$$
\vartheta_{i t}:=u_{y i t}-\rho_{i} u_{y i t-1}+\sum_{j=1}^{p-1} \phi_{i j} \Delta u_{y i t-j}
$$

Simple resampling is applied to the empirically white noise residuals $\vartheta_{i t}$, and the bootstrap residuals $u_{i t}^{*}$ constructed recursively using the estimated coefficients of (10). The validity of this approach hinges upon two assumptions the memory of the residuals: linear form and length smaller than the maximum lag of the AR polynomial. In PPP's approach no assumptions on the form of the memory are necessary, while clearly the length of the memory is assumed to be adequately captured by the size of the blocks being resampled.

\section{Monte Carlo evaluation}

\subsection{Design}

Our Monte Carlo experiment is based on a generalisation to dependent panels of the classic Engle and Granger (1987) Data Generating Process (DGP). The panel structure is closely related to those used by, e.g., Gengenbach et al. (2006) and Westerlund (2008), with cross-section dependence assumed to be due to unobserved common factors. Note that, differently from the Bai and $\mathrm{Ng}$ (2004) approach, the common factors are not considered to be of interest by themselves; there is no need, and thus no attempt is made, to estimate them.

Before proceeding any further we need to make clear that panel structures are intrinsically complex, so that complete designs are practically unfeasible. Hence, our aim will be that of defining a design which, though necessarily uncomplete, may be described as empirically relevant.

In the spirit of conditional modelling, and consistently with the set-up described in section 3.2 , we assume a variable of interest, $Y$, known to be linked in each unit $i$ of a panel by a linear, possibly cointegrating, relationship to a right-hand side variable ${ }^{11} X$ :

$$
y_{i t}=\mu_{0 i}+\beta_{i} x_{i t}+u_{i t}^{y}
$$

where $i=1, \ldots, N, t=1, \ldots, T$. The errors $u_{i t}^{y}$ are assumed to have a common factor structure, causing cross-section dependence:

$$
u_{i t}^{y}=\epsilon_{i t}^{y}+\gamma_{i}^{y} F_{t}^{y} .
$$

Both the common factor $F_{t}^{y}$ and the idiosyncratic errors $\epsilon_{i t}^{y}$ are generated by AR processes:

$$
\begin{aligned}
\epsilon_{i t}^{y} & =\varphi_{i} \epsilon_{i t-1}^{y}+e_{i t}^{y}, \quad e_{i t}^{y} \sim N\left(0, \sigma_{y i}^{2}\right) \\
F_{t}^{y} & =\varphi_{C} F_{t-1}^{y}+\eta_{t}^{y}, \quad \eta_{t}^{y} \sim N(0,1)
\end{aligned}
$$

\footnotetext{
${ }^{11}$ Exploratory simulations showed the performances of the test to be independent on the number of independent variables.
} 
where $\sigma_{y i}^{2} \sim$ Uniform $(0.50,0.75)$, fixed across simulations. Under cointegration the $\varphi_{i}^{\prime} s$ are generated as Uniform $(0.4,0.6)$ across units and analogously kept fixed across simulations, while $\varphi_{C}=0.5$. Under no cointegration the common factor $F_{t}^{y}$ is a unit root process $\left(\varphi_{C}=1\right)$, while for the $\varphi_{i}^{\prime} s$ we consider two scenarios, A and B:

A) In the first scenario the autoregressive coefficients of the idiosyncratic shocks, $\varphi_{i}$, are generated as Uniform $(0.4,1.0)$, so that the $y_{i}^{\prime} s$ are cointegrated across most (or possibly all) units. In all units where $\varphi_{i}<1$ long-run growth is driven by the common factor only.

B) In the second one $\varphi_{i}=1 \forall i$, so that the $y_{i}^{\prime} s$ are not cointegrated across units. Long-run growth is driven in all units by two non-stationary stochastic trends, one common across units and the other idiosyncratic.

In both scenarios the loadings are generated as $\gamma_{i}^{y} \sim \operatorname{Uniform}(1.0,3.0)$ fixed across replications, while with no loss of generality we set $\mu_{0 i}=\beta_{i}=1 \forall i$.

The right-hand side variable, $X$, assumed to be the cumulated sum of idiosyncratic random noise in the simplified set-up of section 3.2, is here generalised to include the effects of common shocks. The first type of shocks, $f_{0}^{x}$, is assumed to have only temporary effects, thus mimicking a common cycle $\left(F_{0}^{x}\right)$ loaded through the coefficients $\gamma_{0 i}^{x}$ to produce in each unit the stationary component, $\Upsilon_{0 i t}$ :

$$
\begin{aligned}
F_{0 t}^{x} & =0.4 F_{0 t-1}^{x}+f_{0 t}^{x} \\
\Upsilon_{0 i t} & =\gamma_{0 i}^{x} F_{0 t}^{x}
\end{aligned}
$$

The second type of shocks, $f_{1}^{x}$, weighted by the loadings $\gamma_{1 i}^{x}$, is instead added to the idiosyncratic ones to produce the non-stationary component, $\Upsilon_{1 i t}$, which drives long-run growth:

$$
\Upsilon_{1 i t}=\sum_{s=1}^{t}\left(\gamma_{1 i}^{x} f_{1 s}^{x}+e_{i s}^{x}\right)
$$

The noises $f_{0 t}^{x}$ and $f_{1 t}^{x}$ are generated as $N(0,1)$, while the idiosyncratic shocks $e_{i t}^{x}$ are $N\left(0, \sigma_{\text {exi }}^{2}\right)$, where $\sigma_{\text {exi }}^{2} \sim$ Uniform $(1.0,1.5)$, fixed across replications. Similarly to the $\gamma_{i}^{y \prime} s$, the factor loadings $\gamma_{0 i}^{x}$ and $\gamma_{1 i}^{x}$ are also Uniform $(1.0,3.0)$ across units, fixed for all experiments. Finally, as in Gonzalo (1994), we allow $x_{i t}$ to receive feedback from the left-hand side variable through coefficients $a_{i} \sim$ Uniform $(0.1,0.4)$ fixed across replications. Summing up:

$$
x_{i t}=\left(1-a_{i} \beta_{i}\right)^{-1}\left[\Upsilon_{0 i t}+\Upsilon_{1 i t}+a_{i}\left(\mu_{0 i}+\epsilon_{i t}^{y}\right)\right]
$$

From the empirical point of view, this DGP is representative of many applications. Our $\mathrm{FH}$ equation is one case, but another obvious example is the case of regional consumption and income, with the common factors given by the trend and cycle in national GDP.

The sample sizes considered in the experiment are also chosen trying to reproduce empirically relevant conditions. Recalling that our dataset includes 18 units and 38 time observations we shall examine $N=5,10,20,40$ and $T=20,40,80$. The longer span is sometimes encountered in practice when quarterly observations are available, while the smaller ones are found with datasets at annual frequency. Needless to say, a long-run analysis with $T=20$ has probably very litlle meaning. It is nevertheless interesting to have an idea of the performances that can be expected in these circumstances, and how much they can be expected to improve increasing the sample size to $T=40$.

In all cases the mean block length of the Stationary Bootstrap will be computed as a simple function of the length of the time sample. Since the robustness of the tests to mean block sizes 
chosen within reasonable ranges has been confirmed by exploratory simulations we will report only the results for mean block $1.75 \sqrt[3]{T}$.

Finally, to strike a balance between experimental precision and computing costs the number of both Monte Carlo simulations and bootstrap redrawings has been set to 1000. Approximate $95 \%$ confidence intervals around 0.05 and 0.10 will thus be respectively given by the intervals $[0.04-0.06]$ and $[0.08-0.12]$.

\subsection{Results}

The results of all simulation experiments are reported in Tables 3-6 below. First of all, we check the performances delivered by Westerlund's (2008) Durbin-Hausman group mean test $D H_{g}$ and by Chang and Nguyen's (2011) IV test. The latter will be computed using the simple instrument generating function used in Chang and Nguyen (2011, p. 19), which deos not require an ordering of the units.

Clearly, a careful analysis of the data would reveal that the application of the IV test might be appropriate only in the case of no cointegration across $y_{i}^{\prime} s$ (scenario B), while the $D H_{g}$ test, which does not allow for common factors in the right-hand side variable, should not be applied at all. However, should either of the tests turn out to be robust to deviations from the assumed dependence structure a simple solution to our testing problem would be available. Unfortunately, this does not turn out to be the case. Somehow surprisingly, the size bias of the IV test (see table 3 ) is rather large and increasing with both $T$ and $N$ not only when the $y_{i}^{\prime} s$ are cointegrated (scenario A), but also when they are not (scenario B). Essentially, in small samples the IV test seems to suffer the sheer presence of a common factor structure. This feature is not revealed by the simulations by Chang and Nguyen (2011), where dependence is introduced through correlated errors.

The performances of the $D H_{g}$ test have been evaluted using a slightly different DGP, as this test would be carried out only if a preliminary analysis would have concluded that no I(1) common factors are present in the estimated residuals. We then fixed the autoregressive coefficient of the common factor $F^{y}$ to $\varphi_{C}=0.9$. The results, presented in table 4, appear almost acceptable with large $T$, but definitely not such with small $T$. Particularly worrying is the tendency of the rejections to increase with the cross-section sample size. For a sample size close to that of our dataset, $T=40$, the Type I error for $N=40$ turns out to be 0.26 , twice as large as that for $N=5$. Hence, increasing the number of units of the panel increases the probability of erronously concluding in favour of the existence of a relationship. This is not surprising: essentially, the dependence across units is only partially removed by the pre-filtering, so that the results are those typical of first generation procedures under dependence (see the review in section 3.1).

We have to conclude that neither the $D H_{g}$ nor the IV test seems suitable for our dataset, characterised by a small time sample size and the likely presence of common factors in the variables. We move then to the results delivered by our bootstrap test.

We examine first the results in case of no cointegration across units, scenario B, for which we can obviously evaluate only Type I errors. From table 5 we can see that for $T=40,80$ the tests based on the median of the individiual $H E G$ statistics $\left(M_{e d} d_{H E G}\right)$ and on the mean $(\overline{H E G})$ are always pratically unbiased (recall that the approximate confidence intervals for $\alpha=0.05$ and $\alpha=0.10$ are respectively $0.04-0.06$ and $0.08-0.12$ ), while for $T=20$ there is a slight positive bias. On the other hand, the test based on the maximum $\left(\operatorname{Max}_{H E G}\right)$ has always the correct size. An important finding is that for fixed $T$ the rejection rates are approximately the same for all cross-section sample sizes. Under scenario A, when $Y$ is cointegrated across units, the results collected in table 6 show that $\overline{H E G}$ and $M e d_{H E G}$ have an essentially similar performance, while 
$\operatorname{Max}_{H E G}$ appears instead oversized. Power is generally high.

Although a detailed comparison of the performances of our test vis-à-vis the IV test is outside the scope of this paper, to complement the experiment discussed at the beginning of this section in which we evaluated the performance of the IV test with our DGP we also run some simulations of our bootstrap test with the DGP used by Chang and Nguyen (2011) (cross-correlated errors, no common factors). As expected, the bootstrap test delivered essentially similar results with this DGP also. Detailed results, not reported here for reasons of space, are available on request.

Summing up, with the possible exception of the $M a x_{H E G}$ test under cross-cointegration, the proposed test seems to enjoy good size and power properties even with very small sample sizes. We can thus try to answer to the question left open by the modelling of the individual economies: do we still have a FH puzzle in the OECD?

Table 3

Size of IV Panel Cointegration Test

\begin{tabular}{|c|c|c|c|c|c|c|c|c|}
\hline & \multicolumn{4}{|c|}{$N$} & \multicolumn{4}{|c|}{$N$} \\
\hline & 5 & 10 & 20 & 40 & 5 & 10 & 20 & 40 \\
\hline$T$ & \multicolumn{4}{|c|}{ A. $\varphi_{i} \in[0.4-1.0]$} & \multicolumn{4}{|c|}{ B. $\varphi_{i}=1 \forall i$} \\
\hline 20 & 0.12 & 0.18 & 0.23 & 0.30 & 0.11 & 0.16 & 0.21 & 0.27 \\
\hline 40 & 0.23 & 0.29 & 0.38 & 0.44 & 0.20 & 0.26 & 0.36 & 0.43 \\
\hline 80 & 0.22 & 0.32 & 0.38 & 0.44 & 0.21 & 0.30 & 0.36 & 0.44 \\
\hline
\end{tabular}

DGP: $Y_{i}$ : cf. (11)-(12), $X_{i}:$ cf. (13)-(15), $\varphi_{C}=1$.

$H_{0}$ : No cointegration; nominal size: 0.05 .

Table 4

Size of $D H_{g}$ Panel Cointegration Test

\begin{tabular}{lcccc}
\hline \hline & \multicolumn{4}{c}{$N$} \\
\cline { 3 - 5 }$T$ & 5 & 10 & 20 & 40 \\
\cline { 3 - 5 } 20 & 0.25 & 0.33 & 0.47 & 0.65 \\
40 & 0.13 & 0.16 & 0.22 & 0.26 \\
80 & 0.10 & 0.10 & 0.10 & 0.12 \\
\hline \hline DGP: $Y_{i}:$ cf. & $(11)-(12) ; X_{i}:$ cf. $(13)-(15)$, \\
$\varphi_{C}=0.9, \varphi_{i}=1 \forall i ;$ \\
$H_{0}:$ No cointegration; nominal size: 0.05.
\end{tabular}


Table 5

Bootstrap Panel Cointegration Tests

Scenario B: $Y$ not cointegrated across units

\begin{tabular}{|c|c|c|c|c|c|c|c|c|c|c|c|c|c|}
\hline \multirow[b]{3}{*}{$T$} & \multirow[b]{3}{*}{$\alpha$} & \multirow{2}{*}{\multicolumn{4}{|c|}{$\frac{\operatorname{Med}_{H E G}}{N}$}} & \multirow{2}{*}{\multicolumn{4}{|c|}{$\overline{H E G}$}} & \multicolumn{4}{|c|}{$\operatorname{Max}_{H E G}$} \\
\hline & & & & & & & & & & & & & \\
\hline & & 5 & 10 & 20 & 40 & 5 & 10 & 20 & 40 & 5 & 10 & 20 & 40 \\
\hline \multirow[t]{2}{*}{20} & 0.05 & 0.09 & 0.08 & 0.08 & 0.09 & 0.08 & 0.09 & 0.10 & 0.10 & 0.08 & 0.07 & 0.07 & 0.05 \\
\hline & 0.10 & 0.14 & 0.14 & 0.15 & 0.15 & 0.14 & 0.14 & 0.16 & 0.17 & 0.12 & 0.10 & 0.10 & 0.09 \\
\hline \multirow[t]{2}{*}{40} & 0.05 & 0.05 & 0.05 & 0.05 & 0.05 & 0.05 & 0.04 & 0.05 & 0.05 & 0.05 & 0.06 & 0.05 & 0.05 \\
\hline & 0.10 & 0.09 & 0.09 & 0.08 & 0.09 & 0.09 & 0.08 & 0.08 & 0.08 & 0.10 & 0.10 & 0.09 & 0.08 \\
\hline \multirow[t]{2}{*}{80} & 0.05 & 0.04 & 0.04 & 0.04 & 0.05 & 0.05 & 0.04 & 0.05 & 0.04 & 0.05 & 0.06 & 0.07 & 0.06 \\
\hline & 0.10 & 0.07 & 0.07 & 0.07 & 0.08 & 0.08 & 0.08 & 0.09 & 0.09 & 0.09 & 0.10 & 0.12 & 0.13 \\
\hline
\end{tabular}

DGP: $Y_{i}$ : cf. (11)-(12); $X_{i}:$ cf. (13)-(15), $\varphi_{C}=1, \varphi_{i}=1 \forall i$;

$M_{e d} d_{H E}, \overline{H E G}, M_{H E G}$ : respectively, median, mean and maximum of the individual $H E G_{i}^{\prime} s$;

$H_{0}:$ No cointegration.

95\% approximate confidence intervals for 0.05 and 0.10 : [0.04 - 0.06], [0.08-0.12].

Table 6

Bootstrap Panel Cointegration Tests

Scenario A: $Y$ cointegrated across units

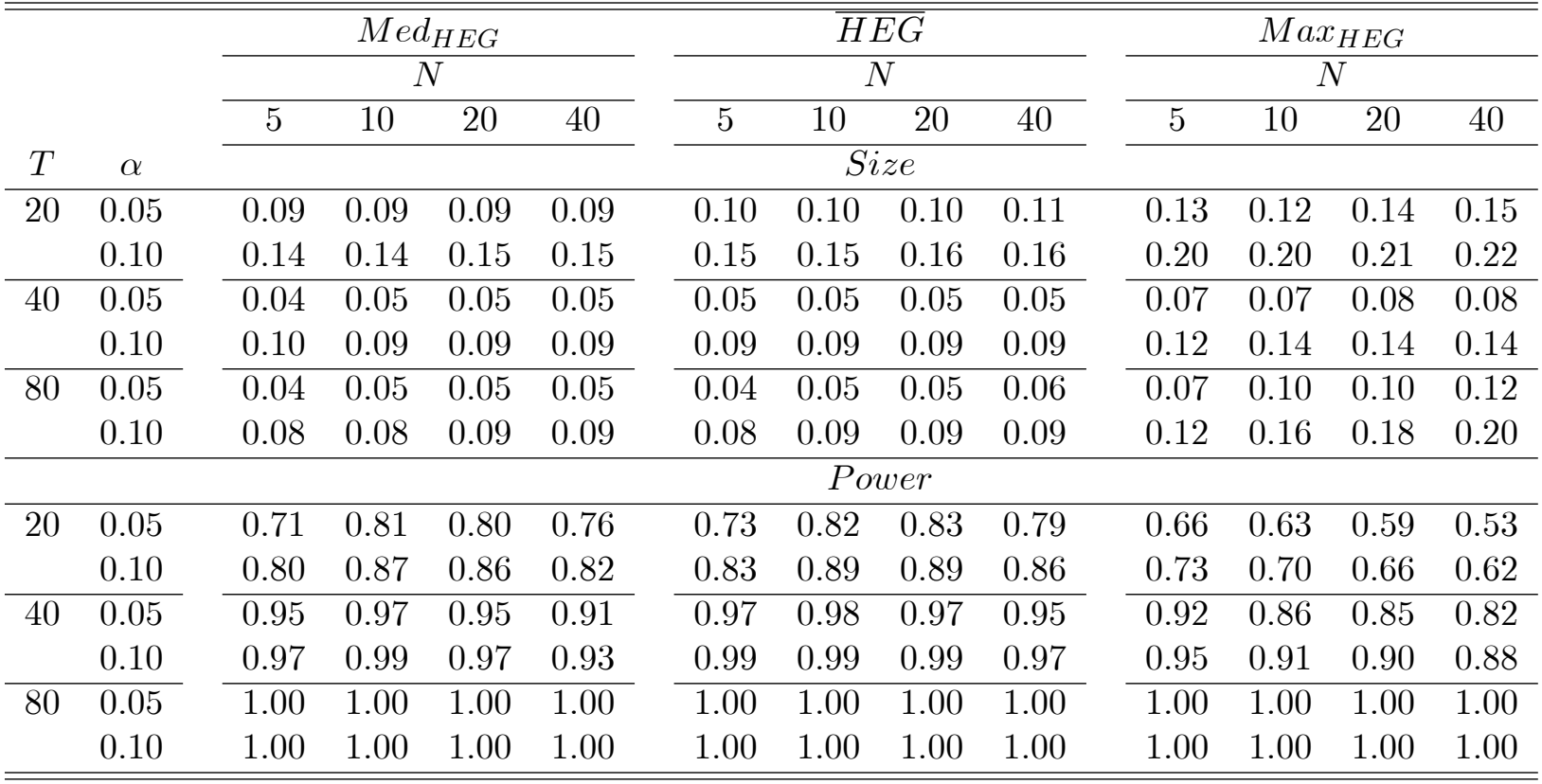

DGP: $Y_{i}:$ cf. (11)-(12); $X_{i}:$ cf. (13)-(15),

Size: $\varphi_{C}=1, \varphi_{i} \sim$ Uniform $(0.4,1.0)$; Power: $\varphi_{C}=0.5, \varphi_{i} \sim \operatorname{Uniform}(0.4,0.6)$;

simbols and abbreviations: see legend of Table 5 . 


\section{A Panel Cointegration test of the FH puzzle}

We can now proceed to apply our new test to the savings-investment data. As it can be appreciated from Table 7, the results are very clear-cut, with $p$-values ranging from $0.44\left(\mathrm{Med}_{H E G}\right.$, entire panel) to $0.77(\overline{H E G} \text {, Eurozone })^{12}$. Obviously, Max $_{H E G}$, which has power in a more restricted direction than both $\overline{H E G}$ and $M e d_{H E G}$, never rejects also; since this result is trivial we do not report the relative $p$-values.

At this point we can quite confidently conclude that investments does not seem to have been linked in the long-run to domestic savings in our sample of OECD economies as a whole. This conclusion holds even more strongly in the financially more integrated Eurozone.

Table 7

The long-run Saving-Investments relationship

in the OECD, 1970-2007

Bootstrap panel cointegration tests

\begin{tabular}{ccc}
\hline \hline & $\overline{H E G}$ & $M e d_{H E G}$ \\
\hline Entire panel & $-2.30[0.63]$ & $-2.23[0.44]$ \\
Panel without Greece & $-2.22[0.65]$ & $-2.23[0.43]$ \\
Eurozone & $-1.71[0.77]$ & $-1.54[0.52]$ \\
\hline \hline
\end{tabular}

in brackets: $p$-values for mean block size $1.75 \sqrt[3]{\bar{T}}=6$,

5000 redrawings.

Entire panel: Austria, Australia, Belgium, Canada, Denmark,

Finland, France, Germany, Greece, Ireland, Italy, Japan,

Netherlands, Portugal, Spain, Sweden, UK, USA;

Eurozone: Austria, Belgium, Finland, France, Germany,

Ireland, Italy, Netherlands, Portugal, Spain

(Greece excluded).

However, from the individual tests (table 1 and 2) we know that a relationship is likely to hold in a few countries. This prompts a natural question: although the puzzle does not hold in the entire panel of 18 countries, can we use our new panel tests to identify some subpanel, wider than that suggested by the individual tests, where it does hold? From our discussion of the various alternative hypothesis we know that this question can be investigated examining the maximum of the cointegration statistics over the units involved. We thus ordered the countries according to the individual $H E G$ tests and, starting with a panel including only the first five units (Australia, Italy, UK, Japan, USA) proceeded sequentially adding one country to the panel at each step and computing the $p$-value of the $\operatorname{Max}_{H E G}$ statistic. In other terms, we compute tests with the same null and alternative hypotheses (respectively, $H_{0}$ :"cointegration in no unit" and $H_{1}$ :"cointegration in all units") on a increasing sequence of nested samples of size $5,6, \ldots, N$. Standard sequential tests, such as those proposed by Smeekes (2010) for the same purpose, keep the sample size and null hypothesis fixed, and change systematically the alternative hypothesis (here it would be in the first step "cointegration at least in unit 1", in the second "cointegration at least in units 1 and 2 ", etc.).

The $p$-values (see Table 8 ) turn out to be always smaller than 0.01 for the first six panels (up to the panel including Australia, Italy, UK, Japan, USA, Portugal, France, Spain, Canada and Ireland). They then remain fairly small but increase regularly at each step when Belgium (0.021), Denmark (0.039), Finland (0.091) and Sweden (0.103) are added. Finally, when the

\footnotetext{
${ }^{12}$ To check the robustness of these results we also computed the $p$-values with mean block 4 and 8 , obtaining estimates differing at most by 0.02 from the reported values.
} 
Netherlands are included in the panel the $p$-value jumps to 0.57 . While this last test is obviously not significant, evaluating the previous ones requires some care. The point is that these tests, computed on a sequence of nested samples, are not independent. Hence, using at each step the same fixed significance level (such as the customary 0.05 ) we would completely lose control of the overall Type I error (also known in the statistical literature as Family Wise Error Rate, FWER). A simple ${ }^{13}$ solution is provided by the Bonferroni principle, which states that a multiple comparison of $N$ separate tests with individual significance level $\alpha_{i}^{B}=\alpha / N, i=1, \ldots, N$ will have FWER bounded by $\alpha$ (see, e.g., Savin, 1984). Since the individual significance levels are severely cut, the risk is obviously that of low power. To evaluate the performances which can be expected in our set-up from a Bonferroni-type test we run a small simulation experiment generating data for 10 units and 40 time observations with the DGP already used above (as in the previous cases, 1000 Monte Carlo replications and Bootstrap redrawings). We computed the $\operatorname{Max}_{H E G}$ test on all subpanels with $1,2, \ldots, 10$ units and obtained the FWER as the proportion of simulations in which at least for one subpanel the $\operatorname{Max}_{H E G}$ test rejected using Bonferroni significance levels $\alpha_{i}^{B}=\alpha / 10$. The results, reported in Table 9, suggest that using Bonferroni individual significance levels the FWER will be somehow smaller than the nominal overall significance level, with power that can nevertheless be expected to be high.

In view of these results, it is pretty obvious that the null hypothesis of no cointegration in at least one unit is not rejected in panel 9, where the $p$-value (0.09) is not significant even on the basis of the usual 0.05 criteria. In the first seven panels the individual significance level to be applied in order to have a 0.10 FWER is $0.10 / 7=0.014$. All the first six $p$-values are much smaller than this threshold, thus suggesting rejection (i.e., we conclude that all countries in these subpanels are cointegrated). When Belgium is added (panel 7) the $p$-value increases to 0.021 , so that the null hypothesis is now not rejected. A different way to express the same concept is that according to the Bonferroni principle in order to reject the null hypothesis in panel 7 we need to accept a FWER larger than $0.021 \times 7=0.147$, definitely an exceedingly large value.

Summing up, this sequential panel procedure allows us to conclude that a saving-investment relationship is likely to hold in ten countries: Australia, Canada, France, Ireland, Italy, Japan, Portugal, Spain, UK, and USA. This group is slightly wider than that selected by the less powerful individual ARDL tests, which under I(1)-ness concluded in favour of cointegration in Australia, Italy, Japan, Portugal, UK (see table 1). The Engle-Granger tests (see table 2) were even more restrictive, supporting cointegration only in Australia, Japan, Portugal and UK.

\footnotetext{
${ }^{13}$ Other approaches are described by Hanck (2009) and Smeekes (2010).
} 
Table 8

The long-run Saving-Investments relationship

in some OECD countries, 1970-2007

Bootstrap panel cointegration tests

\begin{tabular}{clc}
\hline \hline Panel & \multicolumn{1}{c}{ Countries } & Max $x_{H E G}$ \\
\hline 1 & Australia, Italy, UK, Japan, USA & $-0.86[0.0000]$ \\
2 & Panel 1 + Portugal & $-0.84[0.0004]$ \\
3 & Panel 2 + France & $-0.76[0.0008]$ \\
4 & Panel 3 + Spain & $-0.44[0.0050]$ \\
5 & Panel 4 + Canada & $-0.41[0.0052]$ \\
6 & Panel 5 + Ireland & $-0.36[0.0058]$ \\
7 & Panel 6 + Belgium & $-0.15[0.0210]$ \\
8 & Panel 7 + Denmark & $-0.03[0.0394]$ \\
9 & Panel 8 + Finland & $0.14[0.0910]$ \\
10 & Panel 9 + Sweden & $0.22[0.1032]$ \\
11 & Panel 10 + Netherlands & $1.20[0.5650]$ \\
\hline \hline
\end{tabular}

$H_{0}$ : cointegration in no country of the panel, against

$H_{1}$ : cointegration in all countries of the panel;

in brackets: bootstrap $p$-values, 5000 redrawings.

Table 9

Rejction rate of Bonferroni

Panel Cointegration Tests

$$
T=40, N=10
$$

\begin{tabular}{|c|c|c|c|}
\hline & Scenario A & \multicolumn{2}{|c|}{ Scenario B } \\
\hline$\alpha$ & $0.05 \quad 0.10$ & 0.05 & 0.10 \\
\hline Size & 0.03 & 0.03 & 0.05 \\
\hline Power & 0.96 & - & - \\
\hline
\end{tabular}

DGP: see Table 3;

Scenario A: Size, $\varphi_{C}=1, \varphi_{i} \sim \operatorname{Uniform}(0.4,1.0)$;

Power, $\varphi_{C}=0.5, \varphi_{i} \sim$ Uniform $(0.4,0.6)$.

Scenario B: $\varphi_{C}=1, \varphi_{i}=1 \forall i$.

For each subpanel of size $n=1,2, \ldots, 10$ :

$H_{0}$ : no cointegration; $H_{1}$ : cointegration in all units;

In most of the countries where a relationship seems to exist the long-run elasticity of investments to savings estimated from the ARDL models is close or even larger than 1 , the value expected under no capital mobility. In two cases (Australia and UK) it is less than 0.70, while in two more (Portugal and USA) it is less than 0.30. However, the variance of ARDL estimates of long-run elasticities cannot be computed, so we do not know how precise these estimates are. Knowing the group of cointegrating countries we can now compute the FM-OLS estimates, for which this information is available. The FM-OLS estimates (table 10) are, with the only exception of USA, always smaller than the ARDL estimates. France, Italy and Japan are the only countries where the FM-OLS estimate of the saving retention ratio is close to 1 . In about 
half of the cases the ARDL and FM-OLS estimates are fairly close, while in the remaining half the differences are rather large. However, it should be kept in mind that the standard errors of the FM-OLS are also quite large.

Although it is advisable to be quite cautious in our conclusions, the impression is thus that, although in some of the OECD countries examined a link is likely to exist, it is also likely to be much weaker than the one-to-one relationship expected in absence of capital movements. Hence, Feldstein's (1982) remark that "The findings of Feldstein and Horioka [...] do not imply that there is no capital mobility [...] it is reasonable to intepret [them] as evidence that there are substantial imperfections in the international capital market and that a very large share of domestic savings tend to remain in the home country" (Feldstein, 1982, p. 3) seems to apply to most of the countries where there is evidence of an equilibrium relationship. The countries where instead investments do not seem to depend on home savings are Austria, Belgium, Denmark, Finland, Germany, Netherlands and Sweden. Size is obviously not a determinant of this clustering, nor is financial openness as measured by the averages of the Chinn-Ito index (Chinn and Ito, 2008; details, not reported here to save space, available on request).

Our conclusion can be summarised as that there is only weak evidence of a stable savinginvestments relationship in the group of OECD countries examined. In view of the financial liberalisation process of the 1980's the next natural step is to test for the existence of a relationship with breaks in the parameters. To this end, our current research is devoted to a generalised version of our test allowing for breaks at unknown dates.

Table 10

Saving and Investments in the long-run:

FM-OLS estimates of the long-run saving retention ratio

\begin{tabular}{cccccc}
\hline \hline Australia & Canada & Denmark & France & Ireland & Italy \\
\hline $0.45[0.11]$ & $0.47[0.17]$ & $0.18[0.28]$ & $0.90[0.40]$ & $0.18[0.28]$ & $0.84[0.19]$ \\
\hline Japan & Portugal & Spain & UK & USA & \\
\hline $1.19[0.11]$ & $0.16[0.16]$ & $0.35[0.65]$ & $0.36[0.24]$ & $0.36[0.15]$ & \\
\hline \hline
\end{tabular}

\section{Conclusions}

We started with a very simple question: is there a long-run savings-investments puzzle in the OECD? Previous answers were not satisfactory either because obsolete (often the datasets studied stopped at the end of the 1990's, exactly when global financial integration accelerated considerably) or metholodogically flawed. We then examined a panel of the 18 core OECD economies for a period as updated as possible (1970-2007) both individually and as a panel.

Individual modelling suggested a long-run relationship to be present in a small minority of the countries, often with rather small saving retention coefficients. To be sure that the failure to detect in more cases a relationship is not a mere consequence of the low power of the tests we developed a novel bootstrap panel cointegration test, showed it analytically to be asymptotically valid in independent panels and by simulation in dependent panels, and applied it to our dataset.

The conclusion is that there is evidence of a long-run savings-investments relationship in about half of the OECD economies examined (Australia, Canada, France, Ireland, Italy, Japan, Portugal, Spain, UK, and USA), but not in the other half (Austria, Belgium, Denmark, Finland, Germany, Netherlands and Sweden) ${ }^{14}$. Except in three cases (France, Italy and Japan), the

\footnotetext{
${ }^{14}$ In Greece the two variables have been linked by a spurious inverse relationship (not surprising in view of the 2009 financial crisis).
} 
long-run elasticity is however much smaller than 1 , the value expected in absence of capital movements. Essentially, in these countries imperfections in financial markets seem to create a partial home bias. Neither size, nor financial openness, as measured by the averages of the Chinn and Ito (2008) index, seem able to explain why the puzzle holds in the first cluster but not in the second. A possibly important issue to be explored is the role of the financial liberalisation process, and associated possible breaks in the long-run saving-investment relationship. To this end we are currently working on the generalisation of the procedure put forth in this paper to the case of breaks at unknown dates.

\section{Appendix}

\subsection{Asympotic validity of the RSB No Cointegration test}

The panel cointegration statistics proposed in this paper are akin to the group mean tests by Pedroni $(1999,2004)$. We will thus analogously investigate the asymptotic properties of the statistics by means of sequential limit arguments with $T$ assumed to grows large prior to $N$. A detailed discussion of the implication of this type of asymptotics can be found in Pedroni (2004).

For convenience, let us first recall the general set-up already introduced in section 3.2. Let $z_{i t}=\left(y_{i t}, x_{i t}\right)^{\prime}$, where $t=1 \ldots T$ and $i=1 \ldots N$ index respectively the time periods and the cross-section units, be integrated bivariate processes such that

$$
\begin{aligned}
& x_{i t}=x_{i t-1}+u_{i t}^{x} \\
& y_{i t}=\beta_{i} x_{i t}+u_{i t}^{y}
\end{aligned}
$$

where $u_{i t}^{x} \sim N\left(0, \sigma_{x i}^{2}\right)$ and $u_{i t}^{y}$ may be either stationary (under cointegration, in which case $\beta_{i}$ is the long-run elasticity of $y_{i t}$ to $x_{i t}$ ) or not (in which case $\beta_{i}$ is the short-run elasticity). Define further for a given unit $i$ the $\mathrm{AR}(1)$-filtered process $v_{i t}$ mapping the null hypothesis of no cointegration through the parameter $\rho_{i}$ :

$$
v_{i t}:=u_{i t}^{y}-\rho_{i} u_{i t-1}^{y} .
$$

To establish the asymptotic validity of our panel bootstrap procedure we first of all need to prove, for a given unit $i$, that the results presented in PPP for unit root tests also hold when the object of interest is a vector of estimated cointegrating residuals. Recalling that in our case the unit root test is applied to the second-step residuals $\widetilde{u}_{i t}$, defined in equation (8), we need to show that the empirical coefficient statistic:

$$
T\left(\widetilde{\rho}_{i}-1\right)=\frac{T^{-1} \sum_{t=2}^{T} \widetilde{u}_{i t-1} \widetilde{\nu}_{i t}}{T^{-2} \sum_{t=2}^{T} \widetilde{u}_{i t-1}^{2}}
$$

where $\widetilde{\nu}_{i t}=\widetilde{u}_{i t}^{y}-\widetilde{\rho}_{i} \widetilde{u}_{i t-1}^{y}$, and the bootstrap coefficient statistic:

$$
T\left(\widetilde{\rho}_{i}^{*}-1\right)=\frac{T^{-1} \sum_{t=2}^{T} \widetilde{u}_{i t-1}^{*} \widetilde{v}_{i t}^{*}}{T^{-2} \sum_{t=2}^{T} \widetilde{u}_{i s-1}^{*^{2}}}
$$

where $\widetilde{u}_{i t}^{*}$ and $\widetilde{v}_{i t}^{*}$ are the analogues of $\widetilde{u}_{i t}$ and $\widetilde{\nu}_{i t}$ in the bootstrap world, have the same limiting distributions.

To this end, we need to assume the error processes and the estimators involved in (Aii) and (Aiii) to satisfy some conditions. More precisely, we assume for each unit $i$ : 
A1 The vector $\eta_{i t}^{\prime}=\left(u_{i t}^{x}, v_{i t}\right)$ is an independent component stationary ergodic process with zero mean and finite variance (see Phillips and Ouliaris, 1990, henceforth PO, condition C1 and eq. 3). Hence, $\eta_{i t}=\sum_{j=-\infty}^{\infty} A_{j} \xi_{t-j}$ with $\sum_{j=-\infty}^{\infty}\left\|A_{j}\right\|<\infty$ and $A(1)=\sum_{j=-\infty}^{\infty} A_{j}$, where the $\xi_{t-j}^{\prime} s$ are i.i.d. $(0, \Sigma)$ with $\Sigma$ positive definite. All stationary ARMA processes satisfy these conditions.

A2 For the vector process $\eta_{i t}$ it holds that $S_{i T}(r)=T^{-1 / 2} \sum_{t=1}^{[T r]} \eta_{i t} \rightarrow B(r), \quad r \in[0,1]$, where $B(r)$ is a bivariate Brownian motion with covariance matrix $\Omega=\lim _{T \rightarrow \infty} T^{-1} E\left[\left(\sum_{t=1}^{T} \eta_{i t}\right)^{\prime}\left(\sum_{t=1}^{T} \eta_{i t}\right)\right]$.

A3 For $v_{i t}$ and $u_{i t}^{y}$ conditions (i)-(v) in PPP hold, so that:

(i) $\mathbb{E}\left|v_{i t}\right|^{6+\delta}<\infty$;

(ii) $\mathbb{E}\left|u_{i t}^{y}\right|^{6+\delta}<\infty$;

(iii) $\left(\alpha\right.$-mixing): $\sum_{k} k^{2}\left[\alpha_{v_{i}}(k)\right]^{\frac{\delta}{6+\delta}}<\infty$;

(iv) if $\rho_{i}=1, \sum_{k} k^{2}\left[\alpha_{u_{i}^{y}}(k)\right]^{\frac{\delta}{6+\delta}}<\infty$;

(v) the spectral density of $v_{i t}, f_{v_{i}}$, satisfies $f_{v_{i}}(0)>0$.

Conditions (i)-(iv) are needed to ensure the asymptotic validity of the Stationary Bootstrap (Politis and Romano, 1994), while condition (v) to exclude the degenerate case $\operatorname{var}\left(\sqrt{T} \bar{v}_{i t}\right)=0$, where $\bar{v}_{i t}=T^{-1} \sum_{t=1}^{T} v_{i t}$ as in PPP.

A4 The estimator $\widehat{\rho}_{i}$ of the $\operatorname{AR}(1)$ coefficient in equation (Ai) satisfies:

$$
\widehat{\rho}_{i}=\rho_{i}+ \begin{cases}o_{p}(1) & \text { if } \rho_{i}<1 \text { (cointegration) } \\ O_{p}\left(T^{-1}\right) & \text { if } \rho_{i}=1 \text { (no cointegration) }\end{cases}
$$

A5 The estimator $\widehat{\beta}_{i}^{d}$ of the cointegrating coefficient satisfies:

$$
\widehat{\beta}_{i}^{d}=\beta_{i}+ \begin{cases}O_{p}\left(T^{-1}\right) & \text { if } \rho_{i}<1 \text { (cointegration) } \\ O_{p}\left(T^{-\frac{1}{2}}\right) & \text { if } \rho_{i}=1 \text { (no cointegration) }\end{cases}
$$

Assumptions A1 ensures that the Stationary Bootstrap can be applied to $\Delta x_{i t}=u_{i t}^{x}$. Assumptions A1-A2 ensure that the no cointegration statistic $T\left(\widetilde{\rho}_{i}-1\right)$ has the same limiting distribution of the coefficient statistic for a unit root (Hansen, 1990, theorem 2). Finally, Assumptions A3-A5 allow us to state Lemma 1 below, which extends to the estimated residuals $\left\{\widehat{\widehat{u}}_{i t}^{d}\right\}$ point $(i)$ of PPP's Lemma 3. Building on Lemma 1, we shall first state Proposition 1, our counterpart of PPP's Theorem 1, and finally, in Propositions 2 and 3, state the asymptotic validity of the bootstrap cointegration and panel cointegration tests.

Note that Propositions 1 and 2 below are on the asymptotic behaviour as $T \rightarrow \infty$ for a given unit $i$; we will introduce the panel dimension in Proposition 3.

Lemma 1 Let $\bar{u}_{i t}^{d}=\widehat{\widehat{u}}_{i t}^{d}-\frac{1}{T-1} \sum_{\tau=2}^{T} \widehat{\widehat{u}}_{i \tau}^{d}$ and $\bar{v}_{i t}=v_{i t}-\frac{1}{T-1} \sum_{\tau=2}^{T} v_{i \tau}$. For a given unit $i$, define $u_{i t}^{d *}$ and $v_{i t}^{*}$, obtained applying the Stationary Bootstrap respectively to $\bar{u}_{i t}^{d}$ and $\bar{v}_{i t}$, and $\mathbb{E}^{*}(\cdot)$ the expectation in the boostrap world. Recall that $\theta_{T}$ is the coefficient of the geometric distribution employed in the resampling algorithm. Then, under Assumptions A3-A5, if $\theta_{T} \rightarrow 0$ and $\sqrt{T} \theta_{T} \rightarrow \infty:$

$$
\mathbb{E}^{*}\left[T^{-1 / 2} \sum_{m=1}^{K_{\lfloor T r\rfloor}} \sum_{s=1}^{L_{m}} \bar{u}_{i \varsigma_{m+s}}^{d}-T^{-1 / 2} \sum_{m=1}^{K_{\lfloor T r\rfloor}} \sum_{s=1}^{L_{m}} v_{i \varsigma_{m+s}}\right]^{2} \rightarrow 0 .
$$


Proof First of all, recall that the residual $\widehat{\widehat{u}}_{i t}^{d}$ from equation (7) can be rewritten as

$$
\begin{aligned}
\widehat{\widehat{u}}_{i t}^{d} & =\widetilde{u}_{i t}-\widehat{\rho}_{i} \widetilde{u}_{i t-1} \\
& =\left(y_{i t}-\widehat{\beta}_{i}^{d} x_{i t}\right)-\widehat{\rho}_{i}\left(y_{i t-1}-\widehat{\beta}_{i}^{d} x_{i t-1}\right) .
\end{aligned}
$$

Expanding $y_{i t}$ as $y_{i t}=\beta_{i} x_{i t}+u_{i t}^{y}$ and in turn $u_{i t}^{y}$ as $u_{i t}^{y}=\rho_{i} u_{i t-1}^{y}+v_{i t}$ we obtain:

$$
\begin{aligned}
\widehat{\widehat{u}}_{i t}^{d} & =u_{i t}^{y}-\hat{\rho}_{i} u_{i t-1}^{y}+\left(\widehat{\beta}_{i}^{d}-\beta_{i}\right) x_{i t}-\hat{\rho}_{i}\left(\widehat{\beta}_{i}^{d}-\beta_{i}\right) x_{i t-1} \\
& =v_{i t}+\left(\rho_{i}-\hat{\rho}_{i}\right) u_{i t-1}^{y}+\left(\widehat{\beta}_{i}^{d}-\beta_{i}\right) x_{i t}-\hat{\rho}_{i}\left(\widehat{\beta}_{i}^{d}-\beta_{i}\right) x_{i t-1} .
\end{aligned}
$$

so that the centred residual $\bar{u}_{i t}^{d}$ turns out to be the sum of the unobservable noise $v_{i t}$ (centred on the mean) and three other terms:

$$
\begin{aligned}
\bar{u}_{i t}^{d}= & \rho_{i} u_{i t-1}^{y}+v_{i t}-\left(\widehat{\beta}_{i}^{d}-\beta_{i}\right)\left(x_{i t}-\frac{1}{T-1} \sum_{\tau=2}^{T} x_{i \tau}\right)+\hat{\rho}_{i}\left(\widehat{\beta}_{i}^{d}-\beta_{i}\right)\left(x_{i t-1}-\frac{1}{T-1} \sum_{\tau=2}^{T} x_{i \tau-1}\right)+ \\
& -\hat{\rho}_{i} u_{i t-1}^{y}+\hat{\rho}_{i} \frac{1}{T-1} \sum_{\tau=2}^{T} u_{i t-1}^{y}-\frac{1}{T-1} \sum_{\tau=2}^{T}\left(\rho_{i} u_{i t-1}^{y}+v_{i t}\right) \\
= & \left(v_{i t}-\frac{1}{T-1} \sum_{\tau=2}^{T} v_{i t}\right)-\left(\widehat{\rho}_{i}-\rho_{i}\right)\left(u_{i t-1}^{y}-\frac{1}{T-1} \sum_{\tau=2}^{T} u_{i \tau-1}^{y}\right)+ \\
& -\left(\widehat{\beta}_{i}^{d}-\beta_{i}\right)\left(x_{i t}-\frac{1}{T-1} \sum_{\tau=2}^{T} x_{i \tau}\right)+\hat{\rho}_{i}\left(\widehat{\beta}_{i}^{d}-\beta_{i}\right)\left(x_{i t-1}-\frac{1}{T-1} \sum_{\tau=2}^{T} x_{i \tau-1}\right)+
\end{aligned}
$$

Taking into account the block structure (cf. steps 2.1-2.4) the (normalized) sum of these residuals can be written as:

$$
\begin{aligned}
T^{-1 / 2} \sum_{m=1}^{K_{\lfloor T r\rfloor}} \sum_{s=1}^{L_{m}} \bar{u}_{i t}^{d}= & T^{-1 / 2} \sum_{m=1}^{K_{\lfloor T r\rfloor}} \sum_{s=1}^{L_{m}}\left(v_{i \varsigma_{m+s}}-\frac{1}{T-1} \sum_{\tau=2}^{T} v_{i t}\right)+ \\
& -T^{-1 / 2} \sum_{m=1}^{K_{\lfloor T r\rfloor}} \sum_{s=1}^{L_{m}}\left(\rho_{i}-\hat{\rho}_{i}\right)\left(u_{i \varsigma_{m+s-1}}^{y}-\frac{1}{T-1} \sum_{\tau=2}^{T} u_{i \tau-1}^{y}\right)+ \\
& -T^{-1 / 2} \sum_{m=1}^{K_{\lfloor T r\rfloor}} \sum_{s=1}^{L_{m}}\left(\widehat{\beta}_{i}^{d}-\beta_{i}\right)\left(x_{i \varsigma_{m+s}}-\frac{1}{T-1} \sum_{\tau=2}^{T} x_{i \tau}\right)+ \\
& T^{-1 / 2} \sum_{m=1}^{K_{\lfloor T r\rfloor}} \sum_{s=1}^{L_{m}} \hat{\rho}_{i}\left(\widehat{\beta}_{i}^{d}-\beta_{i}\right)\left(x_{i \varsigma_{m+s-1}}-\frac{1}{T-1} \sum_{\tau=2}^{T} x_{i \tau}\right) \\
= & A+B+C+D .
\end{aligned}
$$

To prove the Lemma we need to show that $B, C$ and $D$ converge to zero uniformly in $r$.

Let us examine first $C$. Following PPP (proof of equation (19), p. 622) we need to show that $\mathbb{E}^{*}\left(C^{2}\right) \rightarrow 0$, or, equivalently (PPP, eq. (26), p. 623) that

$$
\mathbb{E}^{*}\left[\left(\widehat{\beta}_{i}^{d}-\beta_{i}\right) \sum_{m=1}^{K_{\lfloor T r\rfloor}} \sum_{s=1}^{L_{m}}\left(x_{i \varsigma_{m+s}}-\frac{1}{T-1} \sum_{\tau=2}^{T} x_{i \tau}\right)\right]^{2}=O_{p}\left(\theta_{T}^{-1} T^{-\frac{3}{2}}\right) .
$$

First of all define $\bar{x}_{i t}=x_{i t}-T^{-1} \sum_{\tau=2}^{T} x_{i \tau}$ and $V_{i m}^{*}=\sum_{s=1}^{L_{m}} \bar{x}_{i \varsigma_{m+s-1}} ;$ note that $\mathbb{E}^{*}\left(V_{i m}^{*}\right)=0(\mathrm{PPP}$, eq. (24), p. 622). Next, recall that $x_{i t}$ is the cumulated sum of the stationary process $u_{i t}^{x}$. Then,

$$
\mathbb{E}^{*}\left(x_{i \varsigma_{m+s-1}}^{2}\right)=\frac{1}{T-1} \sum_{t=2}^{T}\left(\sum_{\tau=1}^{t} u_{i \tau}^{x}\right)^{2}=O_{p}(T)
$$


so that

$$
\mathbb{E}^{*}\left(\bar{x}_{i \varsigma_{m+s-1}}^{2}\right)=\operatorname{Var}^{*}\left(\bar{x}_{i \varsigma_{m+s-1}}\right) \leq \mathbb{E}^{*}\left(x_{i \varsigma_{m+s-1}}^{2}\right)=O_{p}(T) .
$$

From this result and PPP eq. (30) we obtain

$$
\mathbb{E}^{*}\left(V_{i m}^{* 2}\right)=\mathbb{E}^{*}\left(\sum_{s=1}^{L_{m}} \bar{x}_{i \varsigma_{m+s-1}}\right)^{2}=O_{p}\left(\theta_{T}^{-2} T\right) .
$$

Since $\mathbb{E}^{*}\left(V_{i m}^{*}\right)=0, \mathbb{E}_{(}\left(\sum_{m=1}^{K_{\lfloor T r\rfloor}} V_{i m}^{*}\right)^{2}=\mathbb{E}^{*}\left(K_{\lfloor T r\rfloor}\right) \mathbb{E}^{*}\left(V_{i m}^{*}\right)^{2}=O_{p}\left(\theta_{T}^{-1} T^{2}\right)$ (PPP, p. 624). Finally, since Assumption A5 ensures that under the null hypothesis of no cointegration $\left(\widehat{\beta}_{i}^{d}-\beta_{i}\right)=$ $O_{p}\left(T^{-\frac{1}{2}}\right)$, it follows that

$$
\mathbb{E}^{*}\left[\left(\widehat{\beta}_{i}^{d}-\beta_{i}\right) \sum_{m=1}^{K_{\lfloor T r\rfloor}} V_{i m}^{*}\right]^{2}=O_{p}\left(\theta_{T}^{-1} T^{-\frac{3}{2}}\right) .
$$

uniformly in $r$.

By Slutsky's theorem the same proof can be applied to $D$, so that

$$
\mathbb{E}^{*}\left[\hat{\rho}_{i}\left(\widehat{\beta}_{i}^{d}-\beta_{i}\right) \sum_{m=1}^{K_{\lfloor T r\rfloor}} V_{i m}^{*}\right]^{2}=O_{p}\left(\theta_{T}^{-1} T^{-\frac{3}{2}}\right) .
$$

uniformly in $r$.

Finally, recall that under the null hypothesis $\rho_{i}=1$ and the $u_{i t}^{y \prime} s$ are a cumulated sum of the stationary process $v_{i t}$, while under assumption A4, $\left(\widehat{\rho}_{i}-\rho_{i}\right)=O_{p}\left(T^{-1}\right)$. Then the same arguments used above apply to $B$, so that

$$
\mathbb{E}^{*}\left[\left(\rho_{i}-\hat{\rho}_{i}\right) \sum_{m=1}^{K_{\lfloor T r\rfloor}} \sum_{s=1}^{L_{m}}\left(u_{i \varsigma_{m+s-1}}^{y}-\frac{1}{T-1} \sum_{\tau=2}^{T} u_{i \tau-1}^{y}\right)\right]^{2}=O_{p}\left(\theta_{T}^{-1} T^{-1}\right)
$$

uniformly in $r$. This completes the proof.

Convergence in mean square of the estimated residuals to the unobservable noise allows us to exploit all the results contained in PPP's Lemmas 3 and 4 . Of particular importance is the convergence in probability in the bootstrap world (denoted by $\stackrel{p^{*}}{\rightarrow}$ ) of the variance of $u_{i t}^{d *}, \widehat{\sigma}_{i T}^{* 2}=\operatorname{Var}^{*}\left(T^{-1} \sum_{t=1}^{T} u_{i t}^{d *}\right)$, to the variance of $v_{i t}^{*}, \sigma_{i T}^{* 2}=\operatorname{Var}^{*}\left(T^{-1} \sum_{t=1}^{T} v_{i t}^{*}\right)$, and to the long-run variance of $v_{i t}, \sigma_{i \infty}^{2}=2 \pi f_{v_{i}}(0)$ :

$$
\begin{aligned}
& \widehat{\sigma}_{i T}^{* 2}-\sigma_{i T}^{* 2} \stackrel{p^{*}}{\rightarrow} 0 \\
& \widehat{\sigma}_{i T}^{* 2}-\sigma_{\infty}^{2} \stackrel{p^{*}}{\rightarrow} 0 .
\end{aligned}
$$

We can now state Proposition 1.

Proposition 1 Define the partial sum process $S_{i T}^{*}(r), r \in[0,1]$, where $S_{i T}^{*}(r)=\frac{1}{\sqrt{T} \widehat{\sigma}_{i r}^{*}} \sum_{t=1}^{[T r]} u_{i t}^{d *}$. Under $A 3-A 5$, if $\theta_{T} \rightarrow 0$ and $\sqrt{T} \theta_{T} \rightarrow \infty$, when $T \rightarrow \infty$ it holds that $S_{i T}^{*}(\cdot) \stackrel{d^{*}}{\rightarrow} W$ in probability, where $\stackrel{d^{*}}{\rightarrow}$ denotes convergence in distribution in the bootstrap world and $W$ is a standard Wiener process. 
Proof First of all, define the process $R_{i T}(r)$, partial sum of the noises $\bar{v}_{i t}$ :

$$
R_{i T}(r)=\frac{1}{\sqrt{T} \sigma_{i T}^{*}} \sum_{m=1}^{k_{\lfloor T r\rfloor}} \sum_{s=1}^{L_{m}} \bar{v}_{i \varsigma_{m+s}}
$$

By (33) in PPP,

$$
R_{i T}(r) \stackrel{d^{*}}{\rightarrow} W
$$

Further, from our Lemma 1 and (Aiv) above and PPP's Lemma 3 it holds that

$$
S_{i T}^{*}(r)-R_{i T}(r) \stackrel{p^{*}}{\rightarrow} 0
$$

uniform in $r$. It then follows that

$$
S_{i T}^{*} \stackrel{d^{*}}{\rightarrow} W
$$

and the proof is complete.

Proposition 1 allows us to extend (either directly or by straightforward application of the continuous mapping theorem) Lemma 5 in PPP (which includes a set of convergence results entirely analogous to those of Lemma 1 in Phillips, 1986) to quantities derived from the estimated cointegrating residuals.

Recalling that $\sigma_{i \infty}^{2}$ is the asymptotic variance of $v_{i t}$, and defining $\sigma^{2}$ as the asymptotic variance of its cumulated sums (see e.g., Phillips, 1986, p. 314) in our case we have:

(a) $T^{-2} \sum_{t=2}^{T} \widetilde{u}_{i t-1}^{* 2} \stackrel{d^{*}}{\rightarrow} \sigma^{2} \int_{0}^{1} W^{2}(r) d r$.

(b) $T^{-1} \sum_{t=2}^{T} \widetilde{u}_{i t-1}^{*} \widetilde{v}_{i t}^{*} \stackrel{d^{*}}{\rightarrow} \frac{1}{2}\left(\sigma^{2} W^{2}(1)-\sigma_{i \infty}^{2}\right)$.

(c) $T^{-3 / 2} \sum_{t=2}^{T} \widetilde{u}_{i t-1}^{*} \stackrel{d^{*}}{\rightarrow} \sigma \int_{0}^{1} W(r) d r$.

(d) $T^{-1 / 2} \sum_{t=1}^{T} \widetilde{v}_{i t}^{*} \stackrel{d^{*}}{\rightarrow} \sigma_{i \infty} W(1)$.

The proofs are based on Proposition 1, consistency of the two-step estimator $\beta_{i}^{d *}$ for the bootstrap population parameter $\widehat{\beta}_{i}^{d}$, and standard arguments. For instance, for result (a):

$$
\begin{aligned}
T^{-2} \sum_{t=2}^{T} \widetilde{u}_{i t-1}^{* 2} & =T^{-2} \sum_{t=2}^{T}\left(y_{i t-1}^{*}-\beta_{i}^{d *} x_{i t-1}^{*}\right)^{2} \\
& =T^{-2} \sum_{t=2}^{T}\left[\left(\sum_{s=1}^{t-1} \Delta y_{i s}^{*}\right)-\beta_{i}^{d *}\left(\sum_{s=1}^{t-1} \Delta x_{i s-1}^{*}\right)\right]^{2} \\
& =T^{-2} \sum_{t=2}^{T}\left[\left(\sum_{s=1}^{t-1}\left(\widehat{\beta}_{i}^{d} \Delta x_{i s}^{*}+u_{i t}^{d *}\right)-\beta_{i}^{d *}\left(\sum_{s=1}^{t-1} \Delta x_{i t-1}^{*}\right)\right]^{2}\right. \\
& =T^{-2} \sum_{t=2}^{T}\left[\left(\widehat{\beta}_{i}^{d}-\beta_{i}^{d *}\right) \sum_{s=1}^{t-1} \Delta x_{i s}^{*}+\sum_{s=1}^{t-1} u_{i t}^{d *}\right]^{2} .
\end{aligned}
$$

Since $\beta_{i}^{d *} \stackrel{p}{\rightarrow} \widehat{\beta}_{i}^{d}$ the limit depends only on $\left(\sum_{s=1}^{t-1} u_{i s}^{d *}\right)^{2}$, which by Proposition 1 and continuos mapping theorem is known to converge to $\sigma^{2} \int_{0}^{1} W^{2}(r) d r$.

We can now state the following proposition, which generalises PPP's Theorem 2 to tests of no cointegration. 
Proposition 2 For a given unit $i$, assume that $\eta_{i t}^{\prime}=\left(u_{i t}^{x}, v_{i t}\right)$ satisfies assumptions A1-A3. Then

$$
\sup _{c \in \mathcal{R}}\left|P^{*}\left(T\left(\widetilde{\rho}_{i}^{*}-1\right) \leq c \mid z_{1} \ldots z_{T}\right)-P_{0}\left(T\left(\widetilde{\rho}_{i}-1\right) \leq c\right)\right| \stackrel{p}{\longrightarrow} 0
$$

where $P^{*}$ is the bootstrap distribution and $P_{0}$ is the probability measure obtained under the true null hypothesis of no cointegration.

Proof Consider (Aii) and (Aiii). By Proposition 1 and the extensione of PPP's Lemma 5 presented in (a)-(d) above, all partial sums appearing in both statistics have the same limit distribution. Hence, by the continuos mapping theorem $T\left(\widetilde{\rho}_{i}-1\right)$ and $T\left(\widetilde{\rho}_{i}^{*}-1\right)$ must have the same limiting distribution also. $\square$

Proposition 2 ensures that a test based on the empirical bootstrap distribution will be asymptotically valid, as this distribution will be close to the true null distribution. The final step is stating the asymptotic validity under independence of a panel no cointegration test computed as the mean of the individual tests.

Proposition 3 Assume that $E\left(\eta_{i t} \eta_{j s}^{\prime}\right)=0$ for each $i \neq j$ and each $s, t$. Then:

$$
\sup _{c \in \mathcal{R}}\left|P^{*}\left(N^{-1} \sum_{i=1}^{N} T\left(\widetilde{\rho}_{i}^{*}-1\right) \leq c \mid z_{i 1} \ldots z_{i T}\right)-P_{0}\left(N^{-1} \sum_{i=1}^{N} T\left(\widetilde{\rho}_{i}-1\right) \leq c\right)\right| \stackrel{p}{\longrightarrow} 0
$$

where $P^{*}$ is the bootstrap distribution and $P_{0}$ is the probability measure obtained under the null hypothesis of no cointegration.

Proof From Proposition 2 and the continuous mapping theorem.

PPP point out that their Theorem 1, which we have extended to cointegration residuals in Proposition 1 above, is general enough to expect tests based on other statistics, such as the Dickey-Fuller test, to be asymptotically valid. Hence, a panel no cointegration test constructed as the mean of the individual $H E G$ tests can be expected to be asymptotically valid also.

\subsection{Data source and definitions}

The data, in national currencies at current prices, have been downloaded from the OECD.stat database. Definitions are as follows:

Investment: Gross capital formation (transaction code: P5S1).

Savings: Net savings (transaction code B8NS1) plus Consumption of fixed capital (transaction code K1S1).

Gross Domestic Product: transaction code B1_GS1. 


\subsection{Unit root tests}

Table A1

Saving and Investments: ADF Unit root tests

\begin{tabular}{lcccccc}
\hline \hline & Austria & Australia & Belgium & Canada & Denmark & Finland \\
\hline $\ln (I / Y)$ & $-2.12[0.24]$ & $-2.82[0.06]$ & $-2.15[0.23]$ & $-1.92[0.32]$ & $-2.26[0.19]$ & $-2.08[0.28]$ \\
$\ln (S / Y)$ & $-1.77[0.39]$ & $-2.49[0.12]$ & $-2.44[0.13]$ & $-2.18[0.21]$ & $-1.87[0.35]$ & $-2.72[0.07]$ \\
\hline & France & Germany & Greece & Ireland & Italy & Japan \\
\hline $\ln (I / Y)$ & $-1.98[0.29]$ & $-2.12[0.24]$ & $-1.88[0.34]$ & $-1.80[0.38]$ & $-2.27[0.18]$ & $-1.18[0.69]$ \\
$\ln (S / Y)$ & $-2.50[0.12]$ & $-2.31[0.17]$ & $-2.67[0.09]$ & $-1.07[0.72]$ & $-1.85[0.35]$ & $-1.97[0.30]$ \\
\hline & Netherlands & Portugal & Spain & Sweden & UK & USA \\
\hline $\ln (I / Y)$ & $-2.94[0.05]^{*}$ & $-3.61[0.006]^{*}$ & $-1.76[0.40]$ & $-2.37[0.16]$ & $-2.85[0.05]^{*}$ & $-2.68[0.09]$ \\
$\ln (S / Y)$ & $-2.08[0.25]$ & $-1.11[0.71]$ & $-2.00[0.29]$ & $-2.54[0.11]$ & $-1.83[0.36]$ & $-1.33[0.61]$ \\
\hline \hline
\end{tabular}

Tests with constant, MacKinnon (1991) one-sided $p$-values in brackets; * : significant at $5 \%$. AR order selection: Ng and Perron (1995).

Table A2

Saving and Investments in the long-run:

ARDL conditional modelling

\begin{tabular}{lcccccc}
\hline \hline & Austria & Australia & Belgium & Canada & Denmark & Finland \\
\hline$p(L M)$ & 0.38 & 0.82 & 0.47 & 0.27 & 0.35 & 0.28 \\
$p_{1}$ & 0 & 0 & 0 & 0 & 0 & 0 \\
$p_{2}$ & - & - & 1 & 1 & 1 & 2 \\
\hline & France & Germany & Greece & Ireland & Italy & Japan \\
\hline$p(L M)$ & 0.62 & 0.20 & 0.94 & 0.52 & 0.99 & 0.72 \\
$p_{1}$ & 0 & 0 & 0 & 0 & 1 & 1 \\
$p_{2}$ & - & 1 & 1 & 1 & 2 & 2 \\
\hline & Netherlands & Portugal & Spain & Sweden & UK & USA \\
\hline$p(L M)$ & 0.99 & 0.77 & 0.77 & 0.20 & 0.40 & 0.17 \\
$p_{1}$ & 0 & 0 & 0 & 1 & 0 & 0 \\
$p_{2}$ & 1 & 1 & 1 & 1 & 1 & 1 \\
\hline \hline
\end{tabular}

$p(L M): p$-value of Breusch-Godfrey LM autocorrelation test of order 1

$p_{1}$ : maximum lag of $\Delta s$

$p_{2}:$ maximum lag of $\Delta i(-: \Delta i$ excluded from the model)

\section{References}

Apergis N., Tsoumas C. (2009) "A survey of the Feldstein Horioka puzzle: What has been done and where we stand" Research in Economics vol. 63, pp. 64-76.

Bai J., Carrion-i-Silvestre J. L. (2005) "Testing panel cointegration with unobservable dynamic common factors" mimeo, University of Barcelona.

Bai J., Ng S. (2004) "A PANIC attack on unit roots and cointegration" Econometrica vol. 72, pp. 1127-1177.

Banerjee, A. (1999) "unit roots and cointegration: an overview" Oxford Bulletin of Economics and Statistics vol. 61, pp. 697-629. 
Banerjee A., Dolado J., Mestre R. (1998) "Error-correction mechanism tests for cointegration in single-equation framework" Journal of Time Series Analysis vol. 19, pp. 267-283.

Banerjee A., Carrion-i-Silvestre J.L. (2006) "Cointegration in panel data with breaks and crosssection dependence" Working Paper Series n. 591, European Central Bank.

Banerjee A., Marcellino M., Osbat C. (2004) "Some cautions on the use of panel methods for integrated series of macro-economic data" The Econometrics Journal vol. 7, pp. 322-340.

Banerjee A., Wagner M. (2009) "Panel methods to test for unit roots and cointegration" in Mills T.C., Patterson K. (Eds.) Palgrave Handbook of Econometrics Volume 2: Applied Econometrics Palgrave Macmillan, London (UK).

Banerjee A., Zangheri P. (2003) "A new look at the Feldstein-Horioka puzzle using an integrated Panel" CEPII, Working Paper No 2003-22.

Blanchard O., Giavazzi F. (2002) "Current account deficits in the Euro area: the end of the Feldstein-Horioka puzzle?" Brookings Papers on Economic Activity vol. 2, pp. 147-209.

Breitung J., Pesaran M.H. (2008) "Unit Roots and cointegration in panels" In Matyas L., Sevestre P. (Eds.) The Econometrics of Panel Data Kluwer Academic Publishers, Dordrecht (NL).

Chakrabarti A. (2006) "The saving-investment relationship revisited: New evidence from multivariate heterogeneous panel cointegration analyses" Journal of Comparative Economics vol. 34 , pp. $402-419$.

Chang Y. (2002) "Nonlinear IV unit root tests in panels with cross-sectional dependency" Journal of Econometrics vol. 110, pp. 261-292.

Chang Y., Nguyen C.M. (2011) "Residual Based Tests for Cointegration in Dependent panels" Journal of Econometrics, In press.

Chang Y., Song W. (2009) "Testing for Unit Roots in Small panels with Short-run and Long-run Cros-sectional Dependencies" Review of Economic Studies vol. 76, pp. 903-935.

Chinn M.D., Ito, H. (2008) "A New Measure of Financial Openness" Journal of Comparative Policy Analysis: Research and Practice, vol. 10, pp. 309-322.

Coakley J., Fuertes A.M., Spagnolo F. (2004) "Is the Feldstein Horioka puzzle history?" The Manchester School vol. 72, pp. 569-590.

Choi C.-Y., Hu L., Ogaki M. (2008) "Robust estimation for structural spurious regressions and a Hausman-type cointegration test" Journal of Econometrics vol. 142, pp. 327-351.

Cochrane D., and Orcutt G.H. (1949) "Application of least squares regression to relationships containing autocorrelated error terms" Journal of the American Statistical Association vol. 44 , pp. 32-61.

Coiteux M., Olivier S. (2000) "The saving retention coefficient in the long run and in the short run: Evidence from panel data" Journal of International Money and Finance vol. 19, pp. $535-548$.

Engle R.F., Granger, C. (1987) "Co-integration and error correction: representation, estimation, and testing" Econometrica vol. 55, pp. 251-276. 
European Commission (2010) Report on Greek government deficit and debt statistics Brussells (BE).

Fachin S. (2007) "Long-Run trends in internal migrations in Italy: a study in panel cointegration with dependent units" Journal of Applied Econometrics vol. 22, pp. 401-428.

Feldstein M., Horioka C. (1980) "Domestic saving and international capital flows" Economic Journal vol. 90, pp. 314-329.

Feldstein M. (1982) "Domestic savings and international capital movements in the long run and in the short run" NBER Working Paper Series n. 947.

Gengenbach C., Palm F., Urbain, J.P. (2006) "Panel cointegration testing in the presence of common factors" Oxford Bulletin of Economics and Statistics vol. 68-S1, pp. 683-719.

Gonzalo J. (1994) "Five alternative methods of estimating long-run equilibrium relationships" Journal of Econometrics vol. 60, pp. 203-233.

Groen J.J.J., Kleibergen F. (2003) "Likelihood-based cointegration analysis in panels of vector error-correction models" Journal of Business and Economic Statistics vol. 21, pp. 295318.

Hanck C. (2009) "For which countries did PPP hold? A multiple testing approach" Empirical Economics vol. 37, pp. 93-103.

Hansen B.E. (1990) "A powerful simple test for cointegration using Cochrane-Orcutt" Working Paper, University of Rochester.

Haug A.H. (1996) "Tests for cointegration: a Monte Carlo comparison" Journal of Econometrics vol. 71, pp. 89-115.

Herwartz H., Xu F. (2010) "A functional coefficient model view of the Feldstein-Horioka puzzle" Journal of International Money and Finance vol. 29, pp. 37-54.

Hoffmann M. (2004) "International capital mobility in the long run and the short run: can we still learn from saving investment data?" Journal of International Money and Finance vol. 23, pp. 113-131.

Ho T. (2002) "A panel Cointegration Approach to the investment-saving correlation" Empirical Economics vol. 27, pp. 91-100.

Jansen W.J. (1996) "Estimating saving-investment correlations: evidence for OECD countries based on error correction model" Journal of International Money and Finance vol. 15, pp. $749-781$.

Kao C. (1999) "Spurious regression and residual-based tests for cointegration in panel data" Journal of Econometrics vol. 90, pp. 1-44.

Kim S.H. (2001) "The saving-investment correlation puzzle is still a puzzle" Journal of International Money and Finance vol. 20, pp. 1017-1034.

Kim H., Oh K., Jeong C. (2005) "Panel cointegration results on international capital mobility in asian economies" Journal of International Money and Finance vol. 24, pp. 71-82. 
Kitamura, Y., Phillips P.C.B. (1997) "Fully modified IV, GIVE and GMM estimation with possibly non-stationary regressors and instruments" Journal of Econometrics vol. 80, pp. 85-123.

Kollias C., Mylonidis N., Paleologou S.-M. (2008) "The Feldstein-Horioka puzzle across EU members: Evidence from the ARDL bounds approach and panel data" International Review of Economics and Finance vol. 17, pp. 380-387.

MacKinnon J. (1991) "Critical values for cointegration tests" in Engle R.F., Granger C. (Eds.) Long-Run Economic Relationships Oxford University Press, Oxford (UK).

Ng S., Perron P. (1995) "Unit Root Tests in ARMA Models with data-dependent methods for the selection of the truncation lag" Journal of the American Statistical Association vol. 90, pp. 268-281.

Obstfeld M., Rogoff K. (2000) "The Six major puzzles in international macroeconomics: is there a common cause?" NBER Working Paper Series n. 7777.

OECD (2002) Forty Years' Experience with the OECD Code of Liberalisation of Capital Movements OECD, Paris.

Palm F.C., Smeekes S., Urbain J.P. (2008) "Cross-sectional dependence robust block bootstrap panel unit root tests" METEOR Research Memoranda N. 48, Maastricht Research School of Economics of Technology and Organization.

Paparoditis E., Politis D.N. (2001) "The continuous-path block bootstrap" In Madan Puri (Ed.) Asymptotics in Statistics and Probability. Papers in honor of George Roussas VSP Publications: Zeist (NL).

Paparoditis E., Politis D.N. (2003) "Residual-based block bootstrap for unit root testing" Econometrica vol. 71, pp. 813-855.

Parker C., Paparoditis E., Politis D.N. (2006) "Unit root testing via the Stationary Bootstrap" Journal of Econometrics vol. 133, pp. 601-638.

Pedroni P. (1999) "Critical Values for cointegration tests in heterogeneous panels with multiple regressors" Oxford Bulletin of Economics and Statistics vol. 61, pp. 653-670.

Pedroni P. (2004) "Panel cointegration, asymptotic and finite sample properties of pooled time series tests with an application to the PPP hypothesis" Econometric Theory vol. 20, pp. $597-625$.

Pelgrin F., Schich S. (2008) "International capital mobility: what do national saving-investment dynamics tell us?" Journal of International Money and Finance vol. 27, pp. 331-344.

Pesaran H.M., Shin Y., Smith R.J. (2001) "Bounds testing approaches to the analysis of level relationships" Journal of Applied Econometrics vol. 16, pp. 289-326.

Phillips P.C.B., Ouliaris S. (1990) "Asympotic properties of residual based tests for cointegration" Econometrica vol. 58, pp. 165-93.

Phillips P.C.B. (1986) "Understanding spurious regression in econometrics" Journal of Econometrics vol. 33, pp. 311-340. 
Politis D.N., Romano J.P. (1994) "The Stationary Bootstrap" Journal of American Statistical Association vol. 89, pp. 1303-1313.

Rao B.B., Tamazian A., Kumar S. (2010) "Systems GMM estimates of the Feldstein-Horioka puzzle for the OECD countries and tests for structural breaks" Economic Modelling vol. 27, pp. 1269-1273.

Rocha F. (2009) "Heterogeneity, saving-investment dynamics and capital mobility in Latin America" Empirical Economics vol. 36, pp. 611-619.

Savin N.E. (1984) "Multiple Hypothesis Testing" In Handbook of econometrics, vol. 2 ch. 14, Griliches Z., Intriligator M. (Eds.), North-Holland, Amsterdam (NL).

Smeekes S. (2010) "Bootstrap sequential tests to determine the stationary units in a panel" Working Paper, Maastricht University.

Taylor A.M. (2002) "A century of current account dynamics" Journal of International Money and Finance vol. 21, pp. 725-748.

Wang S.H., Rosa C. (2010) "A new solution to spurious regressions" Working Paper, Université Catholique de Louvain.

Westerlund J. (2008) "Panel cointegration tests of the Fisher effect" Journal of Applied Econometrics vol. 23, pp. 193-233.

Westerlund J., Constantini M. (2009) "Panel cointegration and the neutrality of money" Empirical Economics vol. 36, pp. 1-26.

Westerlund J., Edgerton D. (2007) "A panel bootstrap cointegration test" Economics Letters vol. 97, pp.185-190. 